\title{
A meta-analysis of changes in brain activity in clinical depression
}

\author{
Susan M. Palmer ${ }^{1}$, Sheila G. Crewther ${ }^{1,2}$, Leeanne M. Carey ${ }^{1,3}$ and The START Project Team \\ ${ }^{1}$ Neurorehabilitation and Recovery, Stroke Division, The Florey Institute of Neuroscience and Mental Health, Melbourne Brain Centre, Heidelberg, VIC, Australia \\ 2 School of Psychological Science, La Trobe University, Bundoora, VIC, Australia \\ ${ }^{3}$ Department of Occupational Therapy, School of Allied Health, La Trobe University, Bundoora, VIC, Australia
}

Edited by:

Leonhard Schilbach, University

Hospital Cologne, Germany

\section{Reviewed by:}

Christian Sorg, Klinikum Rechts der

Isar Technische Universität München

Germany

Felix Hoffstaedter, Heinrich-Heine

University Düsseldorf, Germany

${ }^{*}$ Correspondence:

Leeanne M. Carey,

Neurorehabilitation and Recovery,

Stroke Division, The Florey Institute of

Neuroscience and Mental Health, 245

Burgundy Street, Heidelberg, VIC

3084, Australia

e-mail: leeanne.carey@florey.edu.au
Insights into neurobiological mechanisms of depression are increasingly being sought via brain imaging studies. Our aim was to quantitatively summarize overlap and divergence in regions of altered brain activation associated with depression under emotionally valenced compared to cognitively demanding task conditions, and with reference to intrinsic functional connectivity. We hypothesized differences reflective of task demands. A co-ordinate-based meta-analysis technique, activation likelihood estimation, was used to analyze relevant imaging literature. These studies compared brain activity in depressed adults relative to healthy controls during three conditions: (i) emotionally valenced (cognitively easy) tasks $(n=29)$; (ii) cognitively demanding tasks $(n=15)$; and (iii) resting conditions $(n=21)$. The meta-analyses identified five, eight, and seven significant clusters of altered brain activity under emotion, cognition, and resting conditions, respectively, in depressed individuals compared to healthy controls. Regions of overlap and divergence between pairs of the three separate meta-analyses were quantified. There were no significant regions of overlap between emotion and cognition meta-analyses, but several divergent clusters were found. Cognitively demanding conditions were associated with greater activation of right medial frontal and insula regions while bilateral amygdala was more significantly altered during emotion (cognitively undemanding) conditions; consistent with task demands. Overlap was present in left amygdala and right subcallosal cingulate between emotion and resting meta-analyses, with no significant divergence. Our metaanalyses highlight alteration of common brain regions, during cognitively undemanding emotional tasks and resting conditions but divergence of regions between emotional and cognitively demanding tasks. Regions altered reflect current biological and system-level models of depression and highlight the relationship with task condition and difficulty.

Keywords: depression, meta-analysis, fMRI, task activation, resting state, cognition, emotion, brain networks

\section{INTRODUCTION}

Depression is a major burden to society currently affecting an estimated 350 million people globally (World Health Organization, 2012). The lifetime prevalence varies widely, from $3 \%$ in Japan to $17 \%$ in the USA, with most countries in the range of 8-12\% (Andrade et al., 2003). A recent survey across 17 countries found that on average 1 in 20 people report having an episode of depression in the previous year (World Health Organization, 2012). The definition for clinically depressed patients used in this meta-analysis included a current diagnosis of depression with a criterion of at least five of the following symptoms most days for at least 2 weeks: depressed or irritable mood, decreased interest or pleasure in daily activities, significant weight change, changes to sleep patterns, changes in activity patterns, fatigue or loss of energy, feelings of guilt/worthlessness, diminished concentration, and thoughts of suicide (American Psychiatric Association, 2013).

In recent times, a rapidly growing number of brain imaging studies, including positron emission tomography (PET) and functional magnetic resonance imaging (fMRI), have reported differences in induced task activations between patients with depressive symptoms and control subjects when performing specified tasks [e.g., Dichter et al. (2009), Hsu et al. (2010), Carballedo et al. (2011), van Eijndhoven et al. (2011), Sexton et al. (2012)]. There are also reported differences when measuring functional connectivity, i.e., coherence of signal based on temporal similarities, between brain regions during a resting-state condition [see Stuhrmann et al. (2011), Wang et al. (2012), for recent review].

In 2008, a comprehensive meta-analysis by Fitzgerald et al. (2008a) quantitatively summarized brain regions with increased or decreased brain activation in depressed patients compared to healthy controls using the activation likelihood estimation (ALE) method. A number of "hypoactive" regions were identified in depressed patients, including frontal and temporal cortex, during emotion tasks. In addition, a relative increase in activity was identified in subcortical and limbic regions. An increase in activity was also reported in the insula and cerebellum with treatment. Unfortunately, at that time, there were few imaging publications involving cognitive tasks and tasks were not considered sufficiently 
homogeneous for formal analysis. Interestingly, a paper from the same group (Fitzgerald et al., 2008b) involving direct comparison of depressed patients and controls performing the Tower of London and an $n$-back cognitive task, reported greater activation in right prefrontal cortical regions. This leads the authors to suggest that "patients with depression may recruit greater brain regions to achieve similar or even poorer task performance than control subjects." Today, there are 15 additional imaging publications involving cognitive tasks (Table 1). Hence, we wish to reanalyze the studies in the Fitzgerald meta-analysis and the 15 additional imaging publications to further explore the relationship between activation under cognition compared to emotion task conditions.

In 2012, Diener et al. (2012) performed an ALE meta-analysis that combined data from tasks defined in the original study as either emotional or cognitive. They found predominantly hypoactive clusters in anterior insula and anterior cingulate cortex, with activation alterations of frontal regions as well as thalamus and striatum. In comparison, meta-analyses of resting-state activity in depressed patients compared to controls found altered activity in bilateral thalamus (Hamilton et al., 2012) as well as striatal and cortical areas (Kühn and Gallinat, 2013). Graham et al. (2013) used ALE and Gaussian-process regression analyses of emotional, cognitive, and resting conditions to compare current neural models of depression outlined below and showed broad support for the limbic-cortical and corticostriatal models of depression.

Over the last decade, at least three non-mutually exclusive neurobiological models of major depressive disorder have been described: limbic-cortical, corticostriatal, and the default mode network. Mayberg (2003) outlined a limbic-cortical model that suggests depression is linked to over-activity in limbic areas traditionally associated with emotional processing and inadequate inhibition by prefrontal areas (Mayberg et al., 1999). This well established model is understood to include lateral and medial prefrontal cortex, orbitofrontal cortex, anterior cingulate cortex, hippocampus, thalamus, and amygdala. The corticostriatal model emphasizes the role of subcortical structures in information processing, with parallel overlapping cortico-striato-pallaidalthalamic loops, and striatal dysfunction associated with symptoms such as psychomotor retardation (Bora et al., 2012). Clinical and research literature also suggest down regulation of the attentionaffected blood oxygenation level dependent (BOLD) response and increased activation when comparing goal-directed task activated areas associated with emotion and cognition conditions in clinically depressed individuals compared to controls (Drevets, 2000; Halari et al., 2009; Pizzagalli, 2011; Chiong et al., 2013; Li et al., 2014). An increased dominance of the default mode network (Raichle et al., 2001) has more recently been linked [Sheline et al. (2009), Hamilton et al. (2011), for review Berman and Jonides (2011), Holtzheimer and Mayberg (2011)] to symptoms of depression where individuals are reported to show increased self-reflective rumination, as opposed to adaptive reflective rumination or task-positive mode. In this context, we were interested in exploring the brain regions that are statistically altered, i.e., show increased or reduced BOLD activation (in context of emotion and cognition studies) or increased or reduced brain activity under resting conditions, in the limbic-cortical, corticostriatal, and the default networks. Our approach was to investigate this through the separate analysis of emotion, cognition, and resting imaging studies, and to identify commonalities and divergence of altered regions across study conditions. While it is recognized that neural substrates underlying different imaging methods, such as BOLD activation and correlation of BOLD fluctuations, may differ, prior meta-analyses support the investigation of neurobiological models based on a broad range of paradigms, including resting-state fMRI and PET (Fitzgerald et al., 2008a; Graham et al., 2013). Moreover, common patterns of distributed brain regions have been characterized despite the complexity and diversity of the imaging methods used (Fitzgerald et al., 2008a).

While it is likely that processing of emotion and cognitive tasks may involve common networks in both depressed patients and controls (Pessoa, 2014), behavioral criteria of depression would suggest that clinical patients need to apply greater conscious effort to successfully complete the same demanding tasks during a depressive episode than when healthy (Berman et al., 2010). Thus, it is reasonable to further hypothesize that tasks classified as cognitively demanding may induce increased activation in appropriate thalamic and frontal brain areas if similar performance level is to be achieved (Haier et al., 1988; Pessoa, 2014). Indeed, level of activation, i.e., hypoactivity or hyperactivity is reported to vary with clinical diagnosis and task difficulty (Carballedo et al., 2011; Diener et al., 2012).

Historically, classification of neuroimaging tasks used in the depression literature have included emotion and more complex cognitive tasks. "Emotion tasks" have been defined as those that required the subject to respond either explicitly or implicitly to emotional stimuli presented visually or verbally (see Table 1, for examples) with low cognitive demands. More difficult "cognitive tasks" included those requiring maintenance and/or manipulation of information in either short-term, long-term or working memory. We have selected only studies that compared patients assessed to be currently depressed by structured clinical interview for DSM IV disorders (First et al., 1995), with control subjects. Patients under remission were not included. DSMIV was used as the criterion as all the studies reviewed were published before the May 2013 release date of DSMV.

In summary, we aimed to review the current literature as a means of updating and further characterizing the effect of clinical depression on functional neural network activity during tasks classified as simple and more emotionally valenced or relatively more difficult cognitive based (Pessoa, 2014), and during resting conditions. Further, we now have the benefit of added features of an upgraded meta-analysis software with improved meta-analysis technique and functionality whereby the results of two metaanalyses can be compared (contrast analysis) (Eickhoff et al., 2011). Using this software, an estimation of the statistically significant areas of cluster overlap, indicative of commonality of activation or correlation differences between clinically depressed patients and healthy controls, can be quantified under several task conditions. Areas of divergence can also be estimated, indicative of differences in areas of activation by the two groups under different tasks or perhaps tasks that vary in difficulty. In particular, we aimed to explore and quantify regions of overlap and divergence in order to advance our understanding of the relative influence of depression on brain regions under these different conditions. 
Table 1 | Table of included studies.

\begin{tabular}{|c|c|c|c|c|c|c|}
\hline Article & $\begin{array}{l}\text { No of } \\
\text { participants }\end{array}$ & $\begin{array}{l}\text { Imaging } \\
\text { mode }\end{array}$ & Task & $\begin{array}{c}\text { Patient } \\
\text { depression } \\
\text { score mean (SD) }\end{array}$ & $\begin{array}{l}\text { Mean (SD) } \\
\text { patient age }\end{array}$ & Medicated \\
\hline $\begin{array}{l}\text { Bremner et al. } \\
\text { (2007) }\end{array}$ & 18D:9HC & $\begin{array}{l}\mathrm{PET}-\left[{ }^{15} \mathrm{O}\right] \\
\mathrm{H}_{2} \mathrm{O}\end{array}$ & $\begin{array}{l}\text { Emotional words (sad/depressive) - recall } \\
\text { of words }\end{array}$ & $16(7)^{a}$ & $40(13)$ & No \\
\hline $\begin{array}{l}\text { Carballedo } \\
\text { et al. (2011) }\end{array}$ & 15D:15HC & fMRI & Emotional face (sad/angry) - matching task & $22.87(4.35)^{a}$ & $39.87(8.57)$ & No \\
\hline $\begin{array}{l}\text { Dichter et al. } \\
\text { (2009) }\end{array}$ & 14D:15HC & fMRI & Emotional (sad) and neutral pictures & $26.9(4.9)^{\mathrm{a}}$ & $34.8(14.3)$ & No \\
\hline Fu et al. (2004) & 19D: $19 H C$ & fMRI & $\begin{array}{l}\text { Emotional faces (sad) - view, asked to } \\
\text { nominate gender }\end{array}$ & $21.1(2.3)^{a}$ & $43.2(8.8)$ & No \\
\hline $\mathrm{Fu}(2007)$ & 19D:19HC & fMRI & $\begin{array}{l}\text { Emotional faces (happy) - view, asked to } \\
\text { nominate gender }\end{array}$ & $21.1(2.3)^{\mathrm{a}}$ & $43.2(8.8)$ & No \\
\hline $\begin{array}{l}\text { Gotlib et al. } \\
\text { (2005) }\end{array}$ & 18D:18HC & fMRI & $\begin{array}{l}\text { Emotional faces (sad/happy) - view, asked } \\
\text { to nominate gender }\end{array}$ & $24.6(8.3)^{\mathrm{C}}$ & 35.2 & 9/18 on medication \\
\hline $\begin{array}{l}\text { Grimm et al. } \\
\text { (2008) }\end{array}$ & 19D:29HC & fMRI & $\begin{array}{l}\text { Emotional pictures - judge } \\
\text { positivity/negativity }\end{array}$ & $33.12^{\mathrm{a}}(7.13)$ & $40.00(9.89)$ & Yes \\
\hline $\begin{array}{l}\text { Kumari et al. } \\
\text { (2003) }\end{array}$ & $6 \mathrm{D}: 6 \mathrm{HC}$ & fMRI & $\begin{array}{l}\text { Emotionally captioned pictures } \\
\text { (positive/negative) - viewed }\end{array}$ & $19.33(1.03)^{\mathrm{a}}$ & 47 (3.59) & $\begin{array}{l}\text { ns But all patients } \\
\text { cited as being } \\
\text { treatment resistant }\end{array}$ \\
\hline $\begin{array}{l}\text { Lawrence et al. } \\
\text { (2004) }\end{array}$ & 9D:11HC & fMRI & $\begin{array}{l}\text { Emotional faces (sad/fearful/happy) - view, } \\
\text { asked to nominate gender }\end{array}$ & $31.8(11.8)^{\mathrm{c}}$ & $41(11)$ & Yes \\
\hline $\begin{array}{l}\text { Mingtian et al. } \\
\text { (2012) }\end{array}$ & 27D:25HC & fMRI & $\begin{array}{l}\text { Emotional faces (fearful/angry) - matching } \\
\text { task }\end{array}$ & $25.11(5.42)^{d}$ & $20.37(1.86)$ & No \\
\hline $\begin{array}{l}\text { Mitterschiffthaler } \\
\text { et al. (2003) }\end{array}$ & 7D:7HC & fMRI & $\begin{array}{l}\text { Pictures - assess positivity of positive and } \\
\text { neutral pictures }\end{array}$ & $33.6(2.5)^{\mathrm{c}}$ & $46.3(8.1)$ & Yes \\
\hline $\begin{array}{l}\text { Mitterschiffthaler } \\
\text { et al. (2008) }\end{array}$ & 17D:17HC & fMRI & Emotional (sad/neutral) STROOP test & $20.88(1.83)^{\mathrm{a}}$ & $39.3(9.4)$ & No \\
\hline $\begin{array}{l}\text { Ritchey et al. } \\
\text { (2011) }\end{array}$ & 22D:14HC & fMRI & $\begin{array}{l}\text { Pictures - rate "pleasantness" of pictures } \\
\text { (positive/negative/neutral) }\end{array}$ & $26.7(6.7)^{\mathrm{a}}$ & $36.1(10.1)$ & Yes \\
\hline $\begin{array}{l}\text { Siegle et al. } \\
(2002)\end{array}$ & 7D:10HC & fMRI & $\begin{array}{l}\text { Words - assess the emotion of positive, } \\
\text { negative, and neutral words }\end{array}$ & $21.6(9.9)^{\mathrm{c}}$ & $34.3(8.8)$ & No \\
\hline
\end{tabular}


Table 1 | Continued

\begin{tabular}{|c|c|c|c|c|c|c|}
\hline Article & $\begin{array}{l}\text { No of } \\
\text { participants }\end{array}$ & $\begin{array}{l}\text { Imaging } \\
\text { mode }\end{array}$ & Task & $\begin{array}{l}\text { Patient } \\
\text { depression } \\
\text { score mean (SD) }\end{array}$ & $\begin{array}{l}\text { Mean (SD) } \\
\text { patient age }\end{array}$ & Medicated \\
\hline $\begin{array}{l}\text { Siegle et al. } \\
(2007)\end{array}$ & 20D:21HC & $\mathrm{fMRI}$ & $\begin{array}{l}\text { Emotional words (positive/negative/ } \\
\text { neutral) - assess personal relevance of }\end{array}$ & $27.3^{c}$ & 38.8 & No \\
\hline $\begin{array}{l}\text { Surguladze } \\
\text { et al. (2005) }\end{array}$ & 16D:14HC & $\mathrm{fMRI}$ & $\begin{array}{l}\text { Emotional faces (happy/sad/neutral) - view, } \\
\text { asked to nominate gender }\end{array}$ & $31.1(10.8)^{c}$ & $42.3(8.4)$ & ns \\
\hline $\begin{array}{l}\text { Surguladze } \\
\text { et al. (2010) }\end{array}$ & 9D:9HC & $\mathrm{fMRI}$ & $\begin{array}{l}\text { Emotional faces (fear/disgust) - view, } \\
\text { asked to nominate gender }\end{array}$ & $31.8(11.8)^{\mathrm{c}}$ & $42.8(7.2)$ & Yes \\
\hline $\begin{array}{l}\text { Townsend et al. } \\
\text { (2010) }\end{array}$ & 15D:15HC & $\mathrm{fMRI}$ & $\begin{array}{l}\text { Emotional faces (sad/fearful) - matching } \\
\text { task or emotion identification }\end{array}$ & $20.1(4.9)^{a}$ & $45.6(11.2)$ & No \\
\hline $\begin{array}{l}\text { Tremblay et al. } \\
\text { (2005) }\end{array}$ & 12D:12HC & $\mathrm{fMRI}$ & $\begin{array}{l}\text { Pictures - rate "pleasantness" of positive, } \\
\text { negative, and neutral pictures }\end{array}$ & $27.75(3.05)^{a}$ & $34.8(13.96)$ & No \\
\hline $\begin{array}{l}\text { Wang et al. } \\
\text { (2008a) }\end{array}$ & 19D:20HC & $\mathrm{fMRI}$ & $\begin{array}{l}\text { Emotional faces (sad/neutral) - view, asked } \\
\text { to detect circle associated with sad } \\
\text { pictures }\end{array}$ & $19.9(5.3)^{a}$ & $39.3(9.0)$ & $11 / 19$ on medication \\
\hline $\begin{array}{l}\text { Wang et al. } \\
\text { (2008b) }\end{array}$ & 12D:20HC & $\mathrm{fMRI}$ & $\begin{array}{l}\text { Emotional faces (sad/neutral) - view, asked } \\
\text { to detect circle }\end{array}$ & $23.7(5.7)^{b}$ & $69.1(6)$ & 9/12 on medication \\
\hline $\begin{array}{l}\text { Yoshimura et al. } \\
\text { (2010) }\end{array}$ & 13D:13HC & $\mathrm{fMRI}$ & $\begin{array}{l}\text { Emotional words - self-referential } \\
\text { judgment of positive and negative } \\
\text { personality words }\end{array}$ & $26.5(6.9)^{c}$ & $37.6(6.2)$ & Yes \\
\hline $\begin{array}{l}\text { Zhong et al. } \\
\text { (2011) }\end{array}$ & 29D:31HC & $\mathrm{fMRI}$ & $\begin{array}{l}\text { Emotional faces (fearful/angry) - matching } \\
\text { task }\end{array}$ & $34.86(5.41)^{d}$ & $20.45(1.82)$ & No \\
\hline \multicolumn{7}{|l|}{ COGNITION } \\
\hline $\begin{array}{l}\text { Audenaert et al. } \\
\text { (2002) }\end{array}$ & 10D:10HC & $\begin{array}{l}\text { SPECT }-{ }^{99 m T C} \\
\text { ECD }\end{array}$ & $\begin{array}{l}\text { Letter fluency test and category fluency } \\
\text { test }\end{array}$ & $27(3.8)^{a}$ & 19-49 year & Yes \\
\hline $\begin{array}{l}\text { Bremner et al. } \\
\text { (2004) }\end{array}$ & 18D:13HC & $\begin{array}{l}\text { PET }-{ }^{99 m} \mathrm{Tc} \\
\mathrm{ECD}\end{array}$ & $\begin{array}{l}\text { Verbal memory encoding task } \\
\text { remembering words }\end{array}$ & $33(9)^{a}$ & $38(2)$ & Yes \\
\hline $\begin{array}{l}\text { de Asis et al. } \\
\text { (2001) }\end{array}$ & $6 \mathrm{D}: 5 \mathrm{HC}$ & $\begin{array}{l}\text { PET }-{ }^{99 m} \mathrm{Tc} \\
\text { ECD }\end{array}$ & Paced word generation & $>30^{a}$ & 70.7 & 4/6 on medication \\
\hline $\begin{array}{l}\text { van Eijndhoven } \\
\text { et al. (2011) }\end{array}$ & $20 \mathrm{D}: 20 \mathrm{HC}$ & $\mathrm{fMRI}$ & Episodic memory task & $21.08(4.03)^{a}$ & $34.1(11.6)$ & Yes \\
\hline $\begin{array}{l}\text { Elliott et al. } \\
\text { (1997) }\end{array}$ & $6 \mathrm{D}: 6 \mathrm{HC}$ & $\begin{array}{l}\text { PET }-{ }^{99 m T C} \\
\text { ECD }\end{array}$ & Tower of London task & $23.8^{a}$ & 34.7 & $5 / 6$ on medication \\
\hline $\begin{array}{l}\text { Fitzgerald et al. } \\
\text { (2008b) }\end{array}$ & 13D:13HC & $\mathrm{fMRI}$ & $\begin{array}{l}\text { Tower of London, } n \text {-back letter memory } \\
\text { task (where } n=2 \text { ) }\end{array}$ & $32.7(11.9)^{b}$ & $38.4(8.1)$ & $11 / 13$ on medication \\
\hline $\begin{array}{l}\text { Harvey et al. } \\
\text { (2005) }\end{array}$ & 10D:10HC & $\mathrm{fMRI}$ & $\begin{array}{l}N \text {-back working memory (where } n=0 \text {, } \\
1,2,3)\end{array}$ & $26.7(4.6)^{b}$ & $33.8(8.4)$ & $5 / 6$ on medication \\
\hline $\begin{array}{l}\text { Holmes et al. } \\
\text { (2005) }\end{array}$ & $10 \mathrm{D}: 9 \mathrm{HC}$ & $\mathrm{fMRI}$ & $\begin{array}{l}\text { AX expectancy performance task. Subjects } \\
\text { asked to respond to letters in sequence, } \\
\text { e.g., } A X\end{array}$ & ns & $32(9.87)$ & ns \\
\hline $\begin{array}{l}\text { Hugdahl et al. } \\
\text { (2004) }\end{array}$ & 12D:12HC & $\mathrm{fMRI}$ & Mental arithmetic & $22.6(3.5)^{a}$ & $32.8(8)$ & Yes \\
\hline $\begin{array}{l}\text { Matsuo et al. } \\
\text { (2007) }\end{array}$ & 15D:15HC & $\mathrm{fMRI}$ & $\begin{array}{l}N \text {-back working memory (where } \\
n=0,1,2)\end{array}$ & $20.3(5.3)^{\mathrm{a}}$ & $34.3(11.5)$ & No \\
\hline
\end{tabular}


Table 1 | Continued

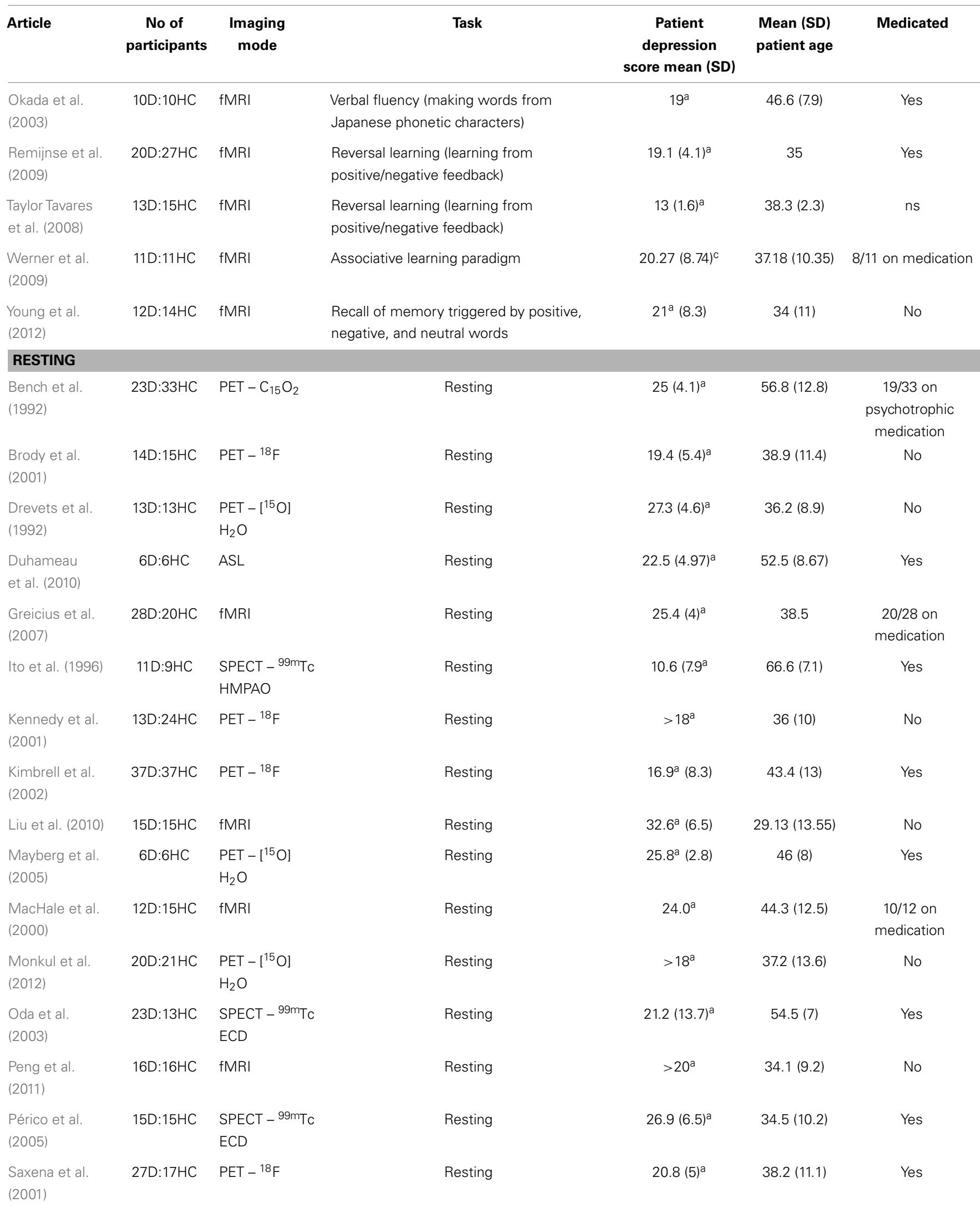


Table 1 | Continued

\begin{tabular}{|c|c|c|c|c|c|c|}
\hline Article & $\begin{array}{c}\text { No of } \\
\text { participants }\end{array}$ & $\begin{array}{l}\text { Imaging } \\
\text { mode }\end{array}$ & Task & $\begin{array}{c}\text { Patient } \\
\text { depression } \\
\text { score mean (SD) }\end{array}$ & $\begin{array}{l}\text { Mean (SD) } \\
\text { patient age }\end{array}$ & Medicated \\
\hline $\begin{array}{l}\text { Skaf et al. } \\
(2002)\end{array}$ & 12D:12HC & $\begin{array}{l}\text { SPECT - }{ }^{99 m T C} \\
\text { ECD }\end{array}$ & Resting & $26.91(6.52)^{a}$ & $41.44(10.67)$ & Yes \\
\hline $\begin{array}{l}\text { Veer et al. } \\
\text { (2010) }\end{array}$ & 19D:19HC & $\mathrm{fMRI}$ & Resting & $14.21(9.62)^{b}$ & $36.2(9.7)$ & No \\
\hline $\begin{array}{l}\text { Videbech et al. } \\
\text { (2001) }\end{array}$ & 42D:47HC & $\begin{array}{l}\text { PET - }\left[{ }^{15} \mathrm{O}\right] \\
\mathrm{H}_{2} \mathrm{O}\end{array}$ & Resting & $>17^{a}$ & $41.9(12.7)$ & No \\
\hline Wu et al. (2011) & 22D:26HC & $\mathrm{fMRI}$ & Resting & $23.2(4.8)^{a}$ & $35(13)$ & No \\
\hline Yao et al. (2009) & 22D:26 HC & $\mathrm{fMRI}$ & Resting & $<35^{a}$ & $38.2(10.2)$ & Yes \\
\hline
\end{tabular}

${ }^{a}$ HAMD Scale 0-56;

${ }^{b}$ MADRS Scale 0-60;

${ }^{c}$ BDI Scale 0-63;

${ }^{d}$ CES-D Scale 0-60.

$D$, depressed patients; $H C$, healthy controls; IAP, international affective picture system; MDD, major depressive disorder; ns, not specified.

Mean patient age is the mean age of the depressed patients. SD is included in brackets if quoted. [ $\left.{ }^{15} \mathrm{O}\right] \mathrm{H}_{2} \mathrm{O}$, radioactively labeled water; ${ }^{99 m} T_{C}$ ECD, I,I-ethyl cysteinate dimmer labeled with technetium-99m; $\mathrm{C}_{15} \mathrm{O}_{2}$, carbon dioxide labeled with ${ }^{15} \mathrm{C} ;{ }^{99 m} \mathrm{TC} H M P A O$, hexamethylpropyleneamineoxime labeled with technetium-99m.

Identification of common and divergent brain regions may better inform current neurobiological models of depression and the mechanisms underlying. Further, it may add to the growing support for common brain regions under emotionally valenced and cognitive conditions (Pessoa, 2008, 2014), in the context of depression. In relation to the direction of increased or decreased differences (investigated via our exploratory meta-analysis), we expected differences in depressed individuals on the basis of capacity limited performance (Pessoa, 2014) suggesting that depressed individuals need to work harder to achieve the same results as normal healthy controls. Finally, based on the quantitative synthesis of brain regions altered in persons suffering from depression under emotion and cognition conditions and at rest, we sought to create brain maps of the regions of interest that may be employed in subsequent imaging analysis of changes in brain networks in populations with depression, such as following stroke.

\section{MATERIALS AND METHODS \\ DATA USED FOR META-ANALYSIS}

Our search included literature up until July 2013 from relevant databases including Medline, Web of Sciences, and PsycINFO using the following search term combinations - "fMRI," "PET," "resting-state MRI," "depression," as well as including articles obtained from the reference list of the selected articles that were reviewed. A total of 3579 articles were identified from the search (Figure 1).

The articles were then reviewed on the basis of strict inclusion and exclusion criteria. Only studies that involved participants with clinical depression (based on a range of assessment scales, see Results for assessment scales used), were compared with normal controls, involved whole-brain analysis, and reported activation or time series correlation co-ordinates in standard space were included. Studies that included a treatment or participants
$<18$ years of age were excluded. Furthermore, all studies were required to utilize imaging techniques of similar temporal sampling including either PET, single-photon emission computed tomography (SPECT), arterial spin labeling (ASL) or functional MRI (fMRI) technology. They were also required to involve an emotionally valenced task (viewing items with emotional content with or without response) or a cognitive task (performing a mental processing task) or resting condition (measuring correlated brain activity or connectivity under non-specified rest condition). Only resting studies that used whole-brain data driven analysis approach such as independent component analysis (ICA) were included. Studies with seed-based approach to analysis were not included. In each study, brain co-ordinates were included where a difference (either increase or decrease in correlated brain activity) between the depressed patients and control subjects was reported. These brain co-ordinates were included as absolute difference co-ordinates in the primary meta-analyses. From a statistical viewpoint, the ALE uses a general linear model without consideration of sign of difference in activation or correlation. Co-ordinates were then further divided into whether the difference reported was an increase or a decrease in activity in depressed patients compared to healthy controls. This allowed us to conduct separate directional meta-analyses for emotion and cognition, or a relative increase or decrease in correlated activity for depressed compared to healthy control subjects for the resting studies.

Based on these criteria, a total of 65 studies were determined to be suitable for inclusion (Figure 1; Table 1). This amounted to a total of 29 emotional processing, 15 cognitive processing, and 21 resting condition publications for review. Studies were categorized into the respective groups based on the original author's descriptive categorization and confirmed by consensus across two of the current authors. In addition, the type of task is briefly categorized in Table 1 of the results. Within the emotional processing 


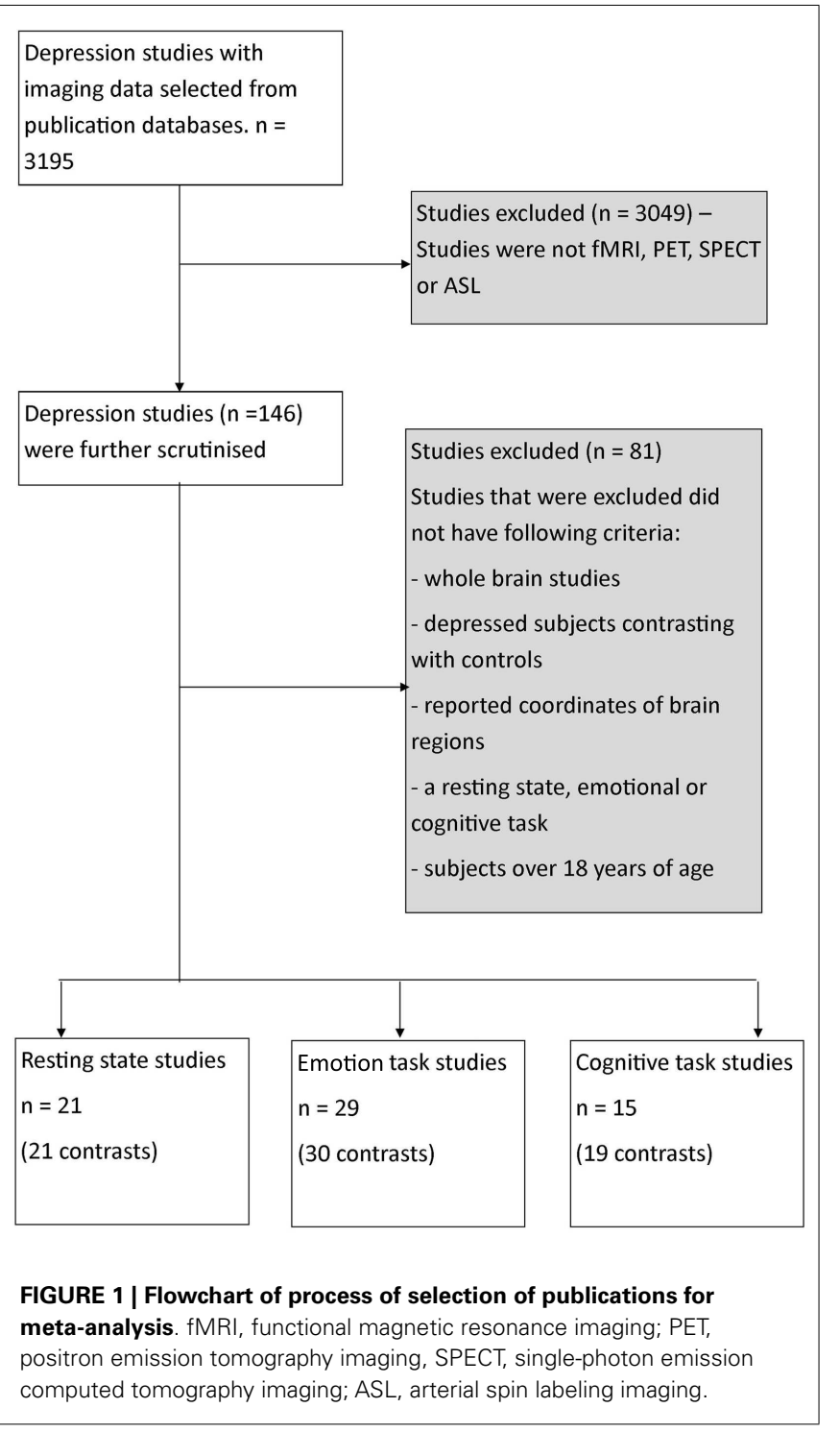

publications, 17 studies were available to study areas where activation was increased and 20 studies available to study areas where activation was decreased. Furthermore, within the cognitive publications, 11 studies were available to study areas where activation was increased and 9 studies available to study areas where activation was decreased. Finally, within the resting publications, 13 studies were available to study areas where correlated activity was increased and 5 studies available to study areas where correlated activity was decreased. Separation of studies according to increased/decreased activation/correlation resulted in a reduced number of studies available for each meta-analysis, which would in turn affect the statistical power of the meta-analysis and have implications when performing contrast analyses across metaanalyses. Our purpose in pooling co-ordinates of difference activity for the primary analyses was to robustly determine spatial location of brain areas involved, irrespective of increased or decreased activity, so that these could be considered as regions of interest in future studies investigating regions disrupted by brain injury such as stroke. This approach also allowed us to conduct contrast analyses to determine regions of overlap and divergence. We pooled coordinates from areas of increased/decreased activity (as absolute difference locations) and thus performed a meta-analysis of brain areas that were altered in depressed subjects relative to controls for each emotional processing, cognitive processing, and resting metaanalysis. A post hoc exploratory analysis was conducted involving separate ALE analyses on the studies divided into increased or decreased activity relative to controls to provide an indication of the direction of change, while recognizing that the number of studies included in these meta-analyses was relatively low.

\section{QUANTITATIVE META-ANALYSIS USING ALE}

The meta-analysis was performed using ALE on the co-ordinates of maximum activation/correlation of the brain regions reported by the selected study. Analysis was performed using GingerALE (version 2.1) software (downloaded from http://brainmap.org/ ale) in Montreal Neurological Institute (MNI) space (Eickhoff et al., 2009, 2012). Co-ordinates reported in Talairach space were converted to MNI space using the icbm2tal transform (Lancaster et al., 2007; Laird et al., 2010).

To minimize within experiment and within group effects we utilized the modified algorithm described in Turkeltaub et al. (2012), which limits the effect of a single experiment. Thus, we were able to include multiple task studies (listed in Table 1) from within the one study. The calculated ALE map was thresholded at $p<0.05$ [corrected for multiple comparisons using the false discovery rate $(\mathrm{FDR})]$. GingerALE provides a recommended cluster size, such that the cluster will not be made up entirely of false positives. This is calculated on the FDR and provides a means to threshold the clusters by size. Accordingly, the clusters were thresholded at $672 \mathrm{~mm}^{3}$ for the emotion meta-analysis, $368 \mathrm{~mm}^{3}$ for the cognition meta-analysis, and $376 \mathrm{~mm}^{3}$ for the resting metaanalysis. Different cluster sizes across studies are influenced by the number of studies, maximum peak, and statistical threshold. We were interested in identifying brain areas that were altered by depression, hence co-ordinates were selected for brain areas showing a difference in depressed patients compared to control subjects (either increased or decreased), implying a difference in brain processes in the depressed patients. Our directional meta-analyses of increased or decreased activation in depressed patients compared to healthy controls were also conducted at the recommended threshold corrected for multiple comparisons.

\section{SUBTRACTION ANALYSIS}

We also performed a subtraction contrast analysis for each of the three meta-analyses, combining two meta-analyses at a time (Eickhoff et al., 2011). In this approach, the two selected ALE analyses are statistically compared and the differences matched with a null-distribution. The null-distribution is generated by pooling all the experiments within the two ALE analyses and then randomly assigning the data to either of the comparison groups and reviewing these groups for 10,000 permutations. This generated $p$ values at the voxel level, indicating significant difference or overlap. These were thresholded at $p<0.05$. A cluster minimum of $10 \mathrm{~mm}^{3}$ was also applied to avoid reporting of incidental overlap or divergence. 
Finally, we explored the potential for overlap across all three meta-analyses through an inspection and tabulation of outputs from each of the meta-analyses in order to describe common patterns. We conducted this descriptive analysis at the recommended cluster threshold nominated as well as at the more lenient and exploratory cluster size threshold of $100 \mathrm{~mm}^{3}$.

\section{RESULTS}

Following a review of the literature using the criteria listed in the methods, we included the papers listed in Table 1. As described in the Section "Materials and Methods," these studies were grouped into emotion tasks, cognition tasks, or resting condition studies. The type of task (emotion, cognition, or resting) undertaken is listed in Table 1. The emotion related tasks primarily involved viewing, recognition, or matching of emotional faces $(n=12)$; assessing or matching emotional words $(n=7)$; assessing positivity/negativity or emotion of pictures $(n=6)$ or emotional STROOP $(n=1)$. The cognition tasks involved verbal and working memory tasks $(n=5)$, reversal/associative learning $(n=3)$, word fluency/generation $(n=3)$, Tower of London $(n=2)$, mental arithmetic $(n=1)$, or performance expectancy $(n=1)$. Thus, the emotion related tasks are cognitively easy while the cognitive tasks are much more demanding. Age of the depressed subjects was typically quoted as a mean age in each of the contributing studies. The overall mean age across the groups did not vary greatly, as the mean of the mean ages of the emotion and cognition and resting studies were 39.5, 38.4, and 41.8 years, respectively. Assessment for the inclusion of the subjects as depressed varied between a number of clinical tests including Hamilton rating scale for depression (HAMD) (Hamilton, 1960),
Montgomery-Asberg depression rating scale (MADRS) (Montgomery and Asberg, 1979), Beck depression inventory (BDI) (Beck et al., 1961), and Center for Epidemiologic Studies Depression Scale (CES-D) (Radloff, 1977).

In the current study, ALE meta-analysis of the results in each category produced a number of clusters localized to a range of different brain areas. Neither hemisphere appeared to dominate in relation to areas activated (Figures 2-4).

\section{EMOTION TASK META-ANALYSIS}

Using the co-ordinates from 29 emotional task papers (which included a total of thirty studies) and the GingerALE metaanalysis technique, 5 significant clusters of difference between patients with clinical depression and healthy controls were identified across studies. This was after using the $672 \mathrm{~mm}^{3}$ threshold recommended by the ALE software (Figure 2). Cluster 1 had three major peaks (or areas of maximum likelihood of difference in depressed patients) that were localized to the left thalamus as well as the left parahippocampal area in BA27 and BA28. Cluster 2 had major peaks in the left amygdala and globus pallidus. Cluster 3 included the right anterior cingulate (BA 25) and the right putamen. The other two clusters were localized to the right amygdala and right insula (BA 13). Clusters are displayed on a template brain (Figure 2).

Results from our exploratory ALE meta-analysis that included studies with co-ordinates that were either increased or decreased in depressed patients relative to controls produced similar results, with clusters identified mostly overlapping clusters reported in the primary study (Figure 2). The clusters from the increased/ decreased activity meta-analyses are indicated in color in the table

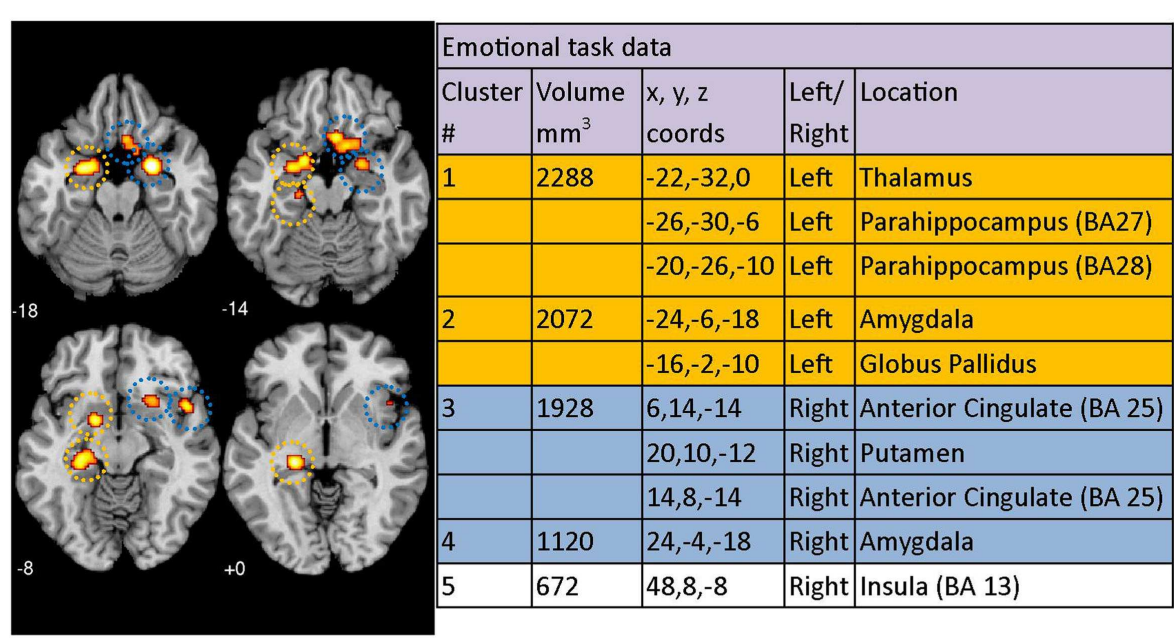

Clusters also found in increased activation sub-study

Clusters also found in decreased activation sub-study

FIGURE 2 | Regions where depressed patients were altered in activity patterns compared to controls when performing an emotional processing task. Clusters listed in the table are taken from the primary meta-analysis comprising all altered co-ordinates. Cluster regions highlighted in orange signify brain areas where depressed patient activation was increased compared to controls. Cluster regions highlighted in blue signify brain areas where patient activation was decreased compared to controls. Co-ordinates $(x, y, z)$ are reported in $\mathrm{MNI}$ space. The number under each brain slice displayed is the MNI " $z$ " co-ordinate. 


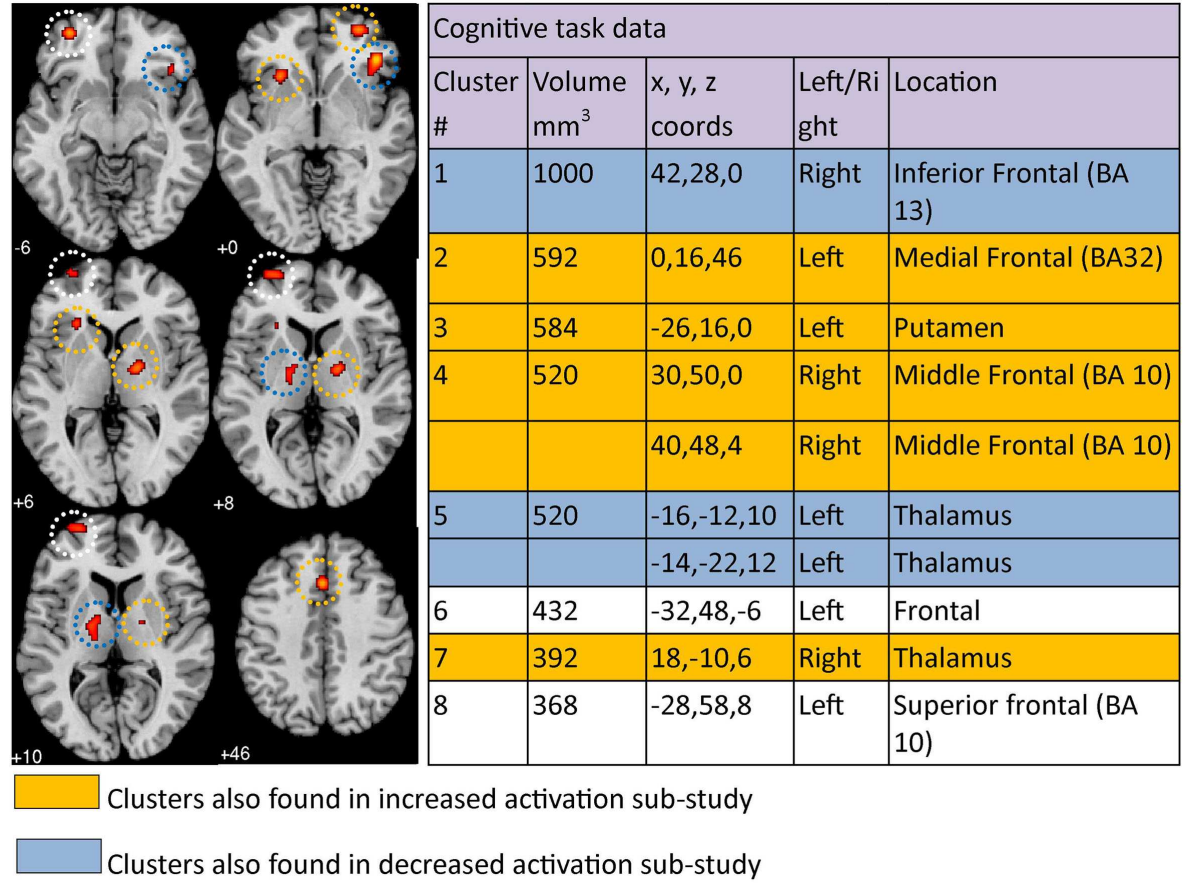

FIGURE 3 | Regions where depressed patients were altered in activity patterns compared to controls when performing a cognitive processing task. Clusters listed in the table are taken from the primary meta-analysis comprising all altered co-ordinates. Cluster regions highlighted in orange signify brain areas where depressed patient activation was increased compared to controls. Cluster regions highlighted in blue signify brain areas where patient activation was decreased compared to controls. Co-ordinates $(x, y, z)$ are reported in $\mathrm{MNI}$ space. The number under each brain slice displayed is the MNI " $z$ " co-ordinate. sections of Figures 2-4, with orange indicating clusters that were identified in the increased activation/correlation meta-analyses and blue indicating clusters identified in the decreased activation/correlation meta-analyses. The clusters are also circled with matching colors on the brain images. In the emotion study, clusters in the left thalamic/parahippocampal and left amygdala/globus pallidus regions were also found in the separate meta-analysis of increased activation during emotional processing. In addition, clusters identified in the right anterior cingulate/putamen and right amygdala were also found in the meta-analysis of decreased activation, while the right insula was not found in either sub-study of increased or decreased activation.

\section{COGNITIVE TASK META-ANALYSIS}

The co-ordinates from 15 cognitive task papers (which included a total of 19 studies) comprised the cognition meta-analysis. Eight significant clusters were identified above the recommended $368 \mathrm{~mm}^{3}$ threshold (Figure 3). The eight clusters were localized to the right inferior frontal region (BA13), left medial frontal area (BA32), left putamen, right middle frontal area (BA 10), left thalamus, left frontal area, right thalamus, and left superior frontal area (BA 10). Activation was increased in the left medial frontal, left putamen, right middle frontal, and right thalamus, but decreased in the right inferior frontal and left thalamus, based on our separate cognition meta-analyses of studies reporting increased and decreased activation. Clusters found in the left frontal and left superior frontal areas in our primary meta-analysis were not found in either sub-study of increased or decreased cognitive clusters. Results can be viewed in Figure 3.

\section{RESTING META-ANALYSIS}

The co-ordinates of significant differences in correlated brain activity or connectivity between clinically depressed and healthy controls from 21 resting condition papers, each reporting 1 study, when analyzed using GingerALE meta-analysis, yielded 7 clusters $>376 \mathrm{~mm}^{3}$ (Figure 4). Cluster 1 had two major peaks, one in the left amygdala and one in the left parahippocampal area (BA34), while cluster 2 had peaks in the left claustrum and putamen. The remaining clusters had maximum peak voxels in the left superior temporal region, right anterior cingulate, right thalamus, left middle frontal area, and right cerebellum. Increased correlated activity was observed in the left amygdala, left parahippocampus, left claustrum, left putamen, right thalamus, and right posterior cerebellum. In comparison, correlated activity was decreased in left superior temporal, right anterior cingulate, and left middle frontal regions under resting conditions. Clusters can be seen mapped to a template brain (Figure 4).

\section{ANALYSIS OF OVERLAP AND DIVERGENCE BETWEEN CLUSTERS ACROSS META-ANALYSES}

A contrast analysis was used to investigate statistically significant overlap and divergence between the clusters generated by 


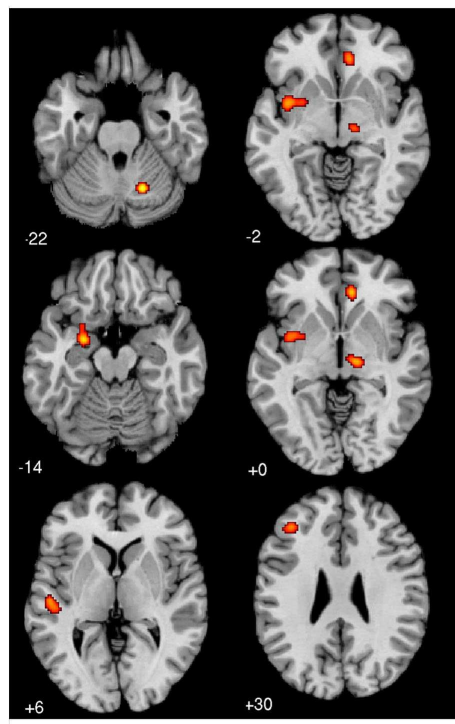

\begin{tabular}{|c|c|c|c|c|}
\hline \multicolumn{5}{|c|}{ Resting-state data } \\
\hline $\begin{array}{l}\text { Cluster } \\
\#\end{array}$ & $\begin{array}{l}\text { Volume } \\
\mathrm{mm}^{3}\end{array}$ & $\begin{array}{l}x, y, z \\
\text { coords }\end{array}$ & $\begin{array}{l}\text { Left/ } \\
\text { Right }\end{array}$ & Location \\
\hline \multirow[t]{2}{*}{1} & 808 & $\begin{array}{l}-24,-8,- \\
14\end{array}$ & Left & Amygdala \\
\hline & & $-24,2,-14$ & Left & $\begin{array}{l}\text { Parahippocampus (BA } \\
34 \text { ) }\end{array}$ \\
\hline \multirow[t]{2}{*}{2} & 808 & $-38,-2,-2$ & Left & Claustrum \\
\hline & & $-28,-2,-2$ & Left & Putamen \\
\hline 3 & 784 & $-52,-24,6$ & Left & $\begin{array}{l}\text { Superior temporal (BA } \\
\text { 41) }\end{array}$ \\
\hline 4 & 576 & $10,32,0$ & Right & $\begin{array}{l}\text { Anterior cingulate (BA } \\
24 \text { ) }\end{array}$ \\
\hline 5 & 576 & $14,-22,0$ & Right & Thalamus \\
\hline 6 & 456 & $-38,32,30$ & Left & Middle frontal (BA 9) \\
\hline 7 & 432 & $\begin{array}{l}18,-68,- \\
22\end{array}$ & Right & Posterior Cerebellum \\
\hline
\end{tabular}

Clusters also found in increased correlation sub-study

Clusters also found in decreased correlation sub-study

FIGURE 4 | Regions where depressed patients were altered in correlated brain activity compared to controls during resting condition. Clusters

listed in the table are taken from the primary meta-analysis comprising all altered co-ordinates. Cluster regions highlighted in orange signify brain areas where depressed patient correlated activity was increased compared to controls. Cluster regions highlighted in blue signify brain areas where patient correlated activity was decreased compared to controls. The number under each brain slice displayed is the MNI " $z$ " co-ordinate.

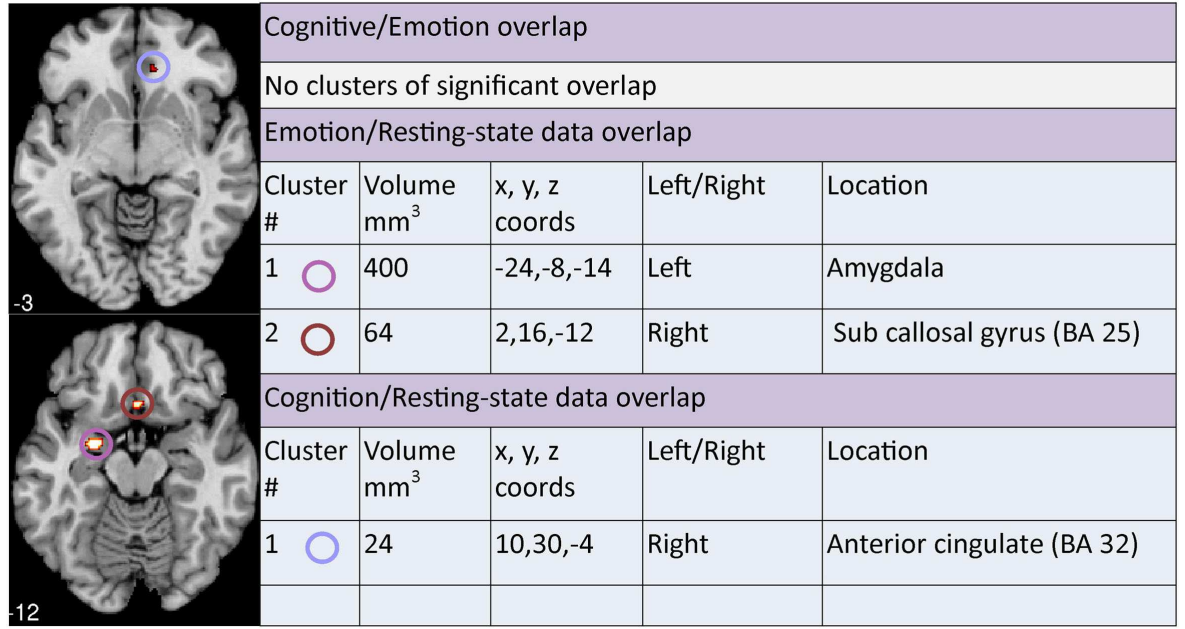

FIGURE 5 | Areas of significant overlap between emotion, cognition, and/or resting-state meta-analyses. Co-ordinates ( $x, y, z)$ are reported in MN space. The number under each brain slice displayed is the MNI " $z$ " co-ordinate.

the three meta-analyses: emotion, cognition, and resting. There were no areas of significant overlap between emotion and cognition meta-analyses (Figure 5). Significant divergence was, however, found in the left amygdala/parahippocampal (BA34) area, close to face processing areas, and right amygdala more in the emotion than the cognition meta-analyses; and in the right medial frontal
(BA10) and right superior temporal/insula area (BA13) more in the cognition than the emotion meta-analyses (Figure 6).

Two clusters of significant overlap were found when comparing the output of the ALE meta-analysis of the resting and emotion conditions (Figure 5). These clusters were found in the left amygdala and right sub callosal gyrus (BA 25). There was 


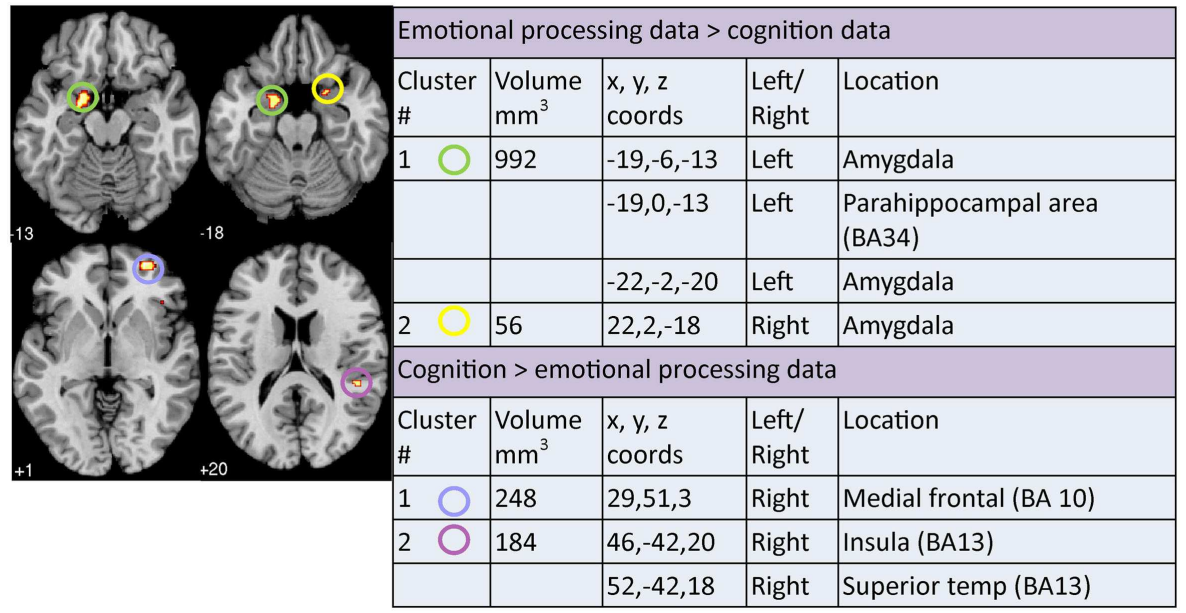

FIGURE 6 | Areas of significant divergence between areas of altered activation when performing an emotion or cognitive-based task in depressed patients compared to controls. Co-ordinates $(x, y, z)$ are reported in MNI space. The number under each brain slice displayed is the MNI " $z$ " co-ordinate.

\begin{tabular}{|l|l|l|l|l|}
\hline \multicolumn{4}{|l|}{ Resting-state $>$ emotional processing data } \\
\hline Cluster \# & $\begin{array}{l}\text { Volume } \\
\mathrm{mm}^{3}\end{array}$ & $\begin{array}{l}\mathrm{x}, \mathrm{y}, \mathrm{z} \\
\text { coords }\end{array}$ & Left/Right & Location \\
\hline No significant divergence \\
\hline Emotional processing data > resting-state data \\
\hline Cluster \# & $\begin{array}{l}\text { Volume } \\
\mathrm{mm}^{3}\end{array}$ & $\begin{array}{l}\mathrm{x}, \mathrm{y}, \mathrm{z} \\
\text { coords }\end{array}$ & Left/Right & Location \\
\hline No significant divergence
\end{tabular}

FIGURE 7 | Areas of significant divergence between areas of altered connectivity during resting-state and when performing an emotion task in depressed patients compared to controls. Co-ordinates $(x, y, z)$ are in $\mathrm{MNI}$ space.

no significant divergence between the resting and emotion metaanalysis (Figure 7) supporting the interpretation that similar brain regions are altered in depressed patients under resting and emotional processing conditions.

Finally, a cluster of significant overlap was found in the right anterior cingulate (BA 32) when comparing resting and cognition meta-analysis cluster outputs (Figure 5). In addition, significant divergence occurred in the left amygdala in resting more than the cognition meta-analyses (Figure 8).

A descriptive exploratory summary of brain areas altered across all three meta-analyses (emotion, cognition, and resting) is shown in Table 2 using common brain area names. As indicated, there were a few areas where two meta-analyses had clusters in the same brain areas but none where all three had clusters in the same brain area when using the recommended threshold. However, after further review of the data for trends, using a reduced cluster size threshold to $100 \mathrm{~mm}^{3}$, some clusters were identified in the same brain region across all three tasks. Clusters were present in the right anterior cingulate in all three meta-analyses, although in the cognitive meta-analysis the anterior cingulate clusters (BA 32/BA24) were 328 and $304 \mathrm{~mm}^{3}$, i.e., below the significance threshold cluster cut off of $368 \mathrm{~mm}^{3}$. Clusters were also present in the left thalamus in all three meta-analyses but this time the cluster in the resting meta-analysis was below threshold. Some common brain regions were significant but in the different hemispheres across conditions, e.g., significant clusters were found in the right thalamus with the resting and cognitive processing tasks but only in the left thalamus for the emotional processing task. Similarly, significant clusters were found in the left putamen with the resting and cognitive processing tasks but only in the right putamen for the emotional processing task.

\section{DISCUSSION MAJOR FINDINGS}

Brain regions of altered activation in patients with depression compared to healthy controls varies with task demand, according to our quantitative co-ordinate based meta-analysis of common and divergent brain regions identified under emotion and cognition conditions. There were no overlapping brain areas showing altered activation with depression compared to controls in our quantitative comparison of cognition and emotion meta-analyses. However, there were brain areas of significant divergence. Significant divergence of activation, greater in the cognitive metaanalysis, was observed in the right medial frontal, insula, and superior temporal regions than in the cognitively undemanding emotion meta-analysis. Involvement of these regions has come to be expected during tasks that are more demanding of memory and attention manipulations (Pessoa, 2014), consistent with our findings. Review of the differences in cognitive demand across the emotion and cognition tasks included in our meta-analyses would suggest that our finding is not unexpected and that future studies need to consider the relative demands of emotion and cognition task conditions. The cognitive tasks included in our meta-analysis were quite demanding, involving verbal memory encoding/working memory, through word fluency and Tower of London tasks. The cognitive load and brain regions involved in 


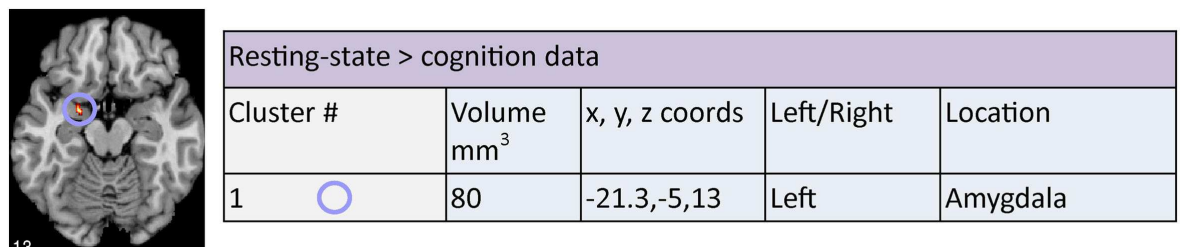

FIGURE 8 | Areas of significant divergence between areas of altered connectivity during resting-state and when performing a cognition task in depressed patients compared to controls. Co-ordinates $(x, y, z)$ are reported in MNI space. The number under each brain slice displayed is the MNI " $z$ " co-ordinate.

Table 2 | Clusters identified in the same brain region across at least two meta-analyses.

\begin{tabular}{lll}
\hline Emotion & Cognition & Resting \\
\hline Right anterior cingulate & (Right anterior cingulate) $^{\text {a }}$ & Right anterior cingulate \\
Left thalamus & Left thalamus & (Left thalamus) \\
Left thalamus & Right thalamus & Right thalamus \\
(Right putamen) & Left putamen & Left putamen \\
Left amygdala & & Left amygdala \\
Left parahippocampus & & Left parahippocampus \\
Right insula & Right insula &
\end{tabular}

${ }^{a}$ Regions in brackets were present within the named meta-analysis at the exploratory cluster level of $100 \mathrm{~mm}^{3}$ but below the ALE suggested cluster threshold.

these type of tasks (Rottschy et al., 2012) is different to that involved in tasks such as recognition and matching of faces, pictures, or words (Posamentier and Abdi, 2003). Our findings support this observation and highlight that there are different brain regions altered in depressed patients compared to controls when performing difficult cognitive tasks compared to simple emotional task conditions.

In relation to simple emotionally valenced tasks, significant divergence was observed in comparison to the cognition metaanalysis; involving greater activation of limbic areas, i.e., bilateral amygdala and parahippocampal area. In addition, simple emotion and resting-state meta-analyses only showed overlap (no divergence), involving amygdala and subcallosal cingulate gyrus (BA 25; also referred to as subgenual cingulate). This is an important result as it highlights alteration of limbic and subcortical areas under both non-taxing emotionally valenced and resting conditions. This was the case even though the emotion studies report alterations in activation while resting-state studies report alteration in the correlation of brain activity such as BOLD fluctuations. Involvement of these subcortical regions during simple emotion compared to cognitively demanding tasks, and during resting conditions might be expected based on task demands and previous meta-analyses (Fitzgerald et al., 2008a; Kühn and Gallinat, 2013). It suggests a level of underlying altered brain activity, previously linked with negative rumination and response to emotionally valenced tasks (Holtzheimer and Mayberg, 2011; Mandell et al., 2014), which is present under non-taxing conditions, irrespective of whether there is a simple emotionally valenced task or not.

Use of the ALE contrast analysis to investigate statistically significant overlap and divergence in emotion, cognition, and resting imaging studies comparing clinically depressed patients and healthy controls is novel. Together our findings emphasize the differences in brain regions altered in depressed patients under different task conditions when performing a higher order more demanding cognition processing task compared to when performing a classic emotionally valenced simple cognitive task or under resting conditions. These findings have implication for interpretation of meta-analysis studies that combine both emotional and cognitive processing tasks in depressed patients. Further, without behavioral data indicating level of difficulty to perform the task or amount of effort for the patient, combined task metaanalyses are more difficult to interpret. Our findings also support the value of conducting separate meta-analyses of cognition and emotion tasks, and resting conditions, with use of contrast analyses to determine overlap and divergence.

Finally, in our exploratory, descriptive analysis across all three neuroimaging meta-analyses, we did not find any common areas of overlap across all three conditions at the cluster corrected level. A trend was, however, noted for the right anterior cingulate and left thalamus regions, as well as in thalamus and putamen of either hemisphere. These findings highlight the involvement of subcortical regions that are implicated in most major models and suggest that activation as well as correlated activity/connectivity from these regions is important.

\section{CHARACTERIZATION OF ALTERED BRAIN REGIONS UNDER SEPARATE EMOTION, COGNITION, AND RESTING CONDITIONS}

Our emotion meta-analysis showed clusters of altered and increased activation in left thalamus/parahippocampus and left amydgala/globus pallidus, while right anterior cingulate/putamen, right amygdala showed a relative decreased activation. Activation of right insula was also altered but not identified within our separate increased or decreased activation studies. These areas are involved in information processing (thalamus) and recognition of emotional faces or scenes (parahippocampal gyrus), and processing of memory and emotional reactions (amydgala, anterior cingulate). Our meta-analytic findings highlight the involvement of limbic as well as striatal areas, consistent with over activity of limbic areas in the limbic-cortical model (Mayberg, 2003) and with involvement of subcortical structures and parallel 
cortico-striato-pallaidal-thalamic loops in the corticostriatal model (Bora et al., 2012). Involvement of right anterior cingulate (BA25), putamen, and the left amygdala are consistent with the findings of Fitzgerald et al. (2008a) for emotion tasks, although increased versus decreased activation varied with induction of positive or negative affect and there were additional brain areas reported by Fitzgerald et al. The brain areas identified as significantly altered in emotional processing in our meta-analysis were also reported as altered in depressed patients in a review of emotional face processing (Stuhrmann et al., 2011). These authors reported hyperactivation to negative and hypo-activation to positive stimuli, particularly in the amygdala, parahippocampal gyrus, putamen, insula, and fusiform face area (Stuhrmann et al., 2011). Increased activation of left amydgala and decreased activation of right amydgala may reflect the positive and negative emotional stimuli employed (see Table 1) or hemispheric specialization, based on evidence that stimulation of right amydgala induced negative emotions while stimulation of left amydgala induced either pleasant or unpleasant emotions (Lanteaume et al., 2007). Voxelbased morphometry has suggested that there are volume changes in the right dorsal anterior insula cortex associated with depression, consistent with involvement of this area (Liu et al., 2014).

Our cognition meta-analysis confirms previous findings showing that frontal areas of the brain are commonly altered when performing a cognitively demanding task in patients with depression (Fitzgerald et al., 2008b; Diener et al., 2012). Involvement of frontal areas in the cognition meta-analysis is not surprising since many of these areas, such as the superior, inferior, and medial frontal gyri are known to be involved in complex cognitive processing in control subjects (Egner, 2009). The tasks in the cognitive studies included in our meta-analysis typically involved multi-stage cognitive processing, working memory, and verbally oriented tasks consistent with this interpretation. More specifically, activation in middle and medial frontal regions was increased in depressed compared to control subjects, while the inferior frontal region was associated with relative decreased activation for depressed subjects. Fitzgerald et al. (2008b) suggested increased activation in prefrontal areas was required by depressed subjects in order to perform the cognitive tasks. Increased activation of certain frontal areas compared to controls, e.g., left medial frontal (BA 32) and right middle frontal (BA 10), support hypotheses based on neural efficiency (Haier et al., 1988; Haier, 2003; Bauer et al., 2014). Decreased activation of right inferior frontal region is consistent with reduced cortical inhibition (Aron et al., 2004) as described in the limbic-cortical model (Mayberg, 2003). Left putamen and bilateral thalamus were also involved in our cognition meta-analysis, consistent with the involvement of these regions in limbic-cortical and corticostriatal models of depression (Mayberg, 2003; Bora et al., 2012). These regions were found in both increased (left putamen, right thalamus) and decreased (left thalamus) activation sub-studies. While involvement of cortical areas is more typically highlighted in relation to cognitive tasks, alteration of these subcortical regions, and in particular bilateral thalami, in depressed patients relative to healthy controls is consistent with the role of the thalamus as a critical component of the frontal cortical-basal ganglia-thalamic circuits. These circuits mediate motivation and emotional drive, planning and cognition for the development and expression of goal-directed behaviors (Haber and Calzavara, 2009). Over-activity in left putamen and right thalamus is consistent with over-activity of limbic areas in the limbic-cortical model of Mayberg (2003).

Our resting meta-analysis showed clusters of altered and increased activity/connectivity in left amygdala, left claustrum, right thalamus, and right posterior cerebellum. These findings need to be interpreted in the context that all studies included in the meta-analysis conducted whole-brain methods of analysis, such as ICA. They represent the common regions of altered connectivity between depressed patients and healthy controls during resting conditions, i.e., when the participant is not performing an explicit task. Increased correlated activity of amygdala, claustrum, and thalamus are consistent with the findings of Fitzgerald et al. (2008a) for resting conditions. In addition, we also found decreased correlated activity in left middle frontal, left superior temporal, and right anterior cingulate regions, also consistent with Fitzgerald's meta-analysis. The similarity of the areas observed is interesting given that we added seven fMRI studies and an ASL study to the meta-analysis, whereas the Fitzgerald et al. (2008a) only included PET and SPECT studies. Hamilton et al. (2012), using their own meta-analysis technique, identified bilateral pulvinar nuclei of the thalamus as having increased activity in depressed patients compared to controls. Similar to Hamilton et al. our results also identified right thalamus as being altered (increased) compared to controls; with left thalamus identified when cluster thresholds were less stringent. The brain areas identified in the resting meta-analysis performed by Kühn and Gallinat (2013) differed from our findings, with increased activity in ventral median prefrontal cortex, left ventral striatum, and left thalamus and decreased activity in left postcentral gyrus, left fusiform gyrus, and left insula. The authors highlighted the need to further explore the behavioral correlates of the observed hyper- and hypo-activation. In summary, increased correlated activity of limbic regions and relative decreased activity of middle frontal regions is consistent with the mood regulating cortico-limbic pathway described by Mayberg $(1997,2003)$. The core role of increased activity of amydgala is consistent with rumination hypotheses (Mandell et al., 2014). There was only minor evidence of differences in correlated activity/connectivity between the clinically depressed patients and healthy controls in the default network.

\section{COMPARISON OF EMOTION, COGNITIVE, AND RESTING META-ANALYSES: OVERLAP AND DIVERGENCE OF BRAIN REGIONS}

To our knowledge, this is the first study that uses the contrast metaanalysis to directly compare and contrast separate meta-analysis findings from studies of altered brain activity in depressed patients compared to healthy controls when performing an emotional or cognitive task or resting condition. Diener et al. (2012) performed a meta-analysis that combined both emotional and cognitive tasks in the one analysis. Combining these conditions was argued on the premise that the emotion and cognition processing centers interact by accessing identical brain regions in broadly overlapping neural networks involving areas such as the amygdala and the prefrontal cortex (Pessoa, 2008, 2014). The expectation was that similar areas of the brain would be affected in depressed patients performing either an emotional or cognitive processing task. Our findings 
do not support this hypothesis. Rather, they not only highlight a lack of significant overlap of altered areas in the brain during the simple emotional and more difficult cognitive tasks but also a significant divergence of brain regions. Specifically, our contrast analysis revealed differential and enhanced involvement of medial frontal and insula regions with the cognitively demanding condition while the simple emotionally valenced condition showed greater involvement of bilateral amygdala. These regions of divergence are consistent with expectation based on the emotional and cognitive demands of the tasks. For example, a relatively greater involvement of right medial frontal, insula, and superior temporal regions for the cognition meta-analysis, compared to emotion meta-analysis, is consistent with the role of these areas in demanding cognition and task difficulty (Pessoa, 2008, 2014). Interestingly, Diener et al. (2012) reported hypoactive clusters in anterior insula under combined conditions while we found a greater involvement (divergence) under cognition compared to emotion conditions. Greater involvement of bilateral amygdala and parahippocampal area in the emotion meta-analysis is consistent with involvement of limbic areas associated with mood regulation (Fitzgerald et al., 2008a; Stuhrmann et al., 2011). While together the regions are similar to those described by Diener et al. (2012), here we highlight the differences under the different meta-analysis task conditions.

The overlap observed between task and resting-state conditions is of interest. Brain regions identified under non-specific resting conditions are often similar to those reported under related task conditions (Fox et al., 2007), thus overlap is not surprising, despite differences in imaging methods. Overlap, together with a lack of divergent regions, during simple emotionally valenced tasks and resting condition is of particular interest. It suggests that the resting state for those with depression (compared to controls) is closely aligned with brain areas also altered during simple but emotionally valenced tasks (rather than involving the more typical default network). While it is recognized that the type of brain activity altered (activation versus correlated activity) varies across meta-analyses, the overlap of brain regions provides confirming evidence of the role of these regions at a systems-level. It may also suggest a common underlying alteration in brain state. For example, this commonality may be linked with underlying rumination, a symptom of depression, likely present in non-specific task (resting) conditions as well as during simple emotionally valenced tasks: increased amydgala activity is linked with all types of rumination (Mandell et al., 2014). The lack of significant divergence may also be expected because both tasks are simple, i.e., not taxing on attentional reserves. The amygdala and subcallosal cingulate have also been associated with depression in a number of studies (Clement et al., 2011), with the subcallosal cingulate identified as a target for antidepressant therapies (Hamani et al., 2011). These regions are part of the mood regulating cortico-limbic pathway originally reported by Mayberg (1997), and highlight the role of subcortical structures. The core role of the left amygdala in depression is supported not only by its presence in the resting meta-analysis but also its overlap with the emotion task, and its divergence between emotion and cognition meta-analyses.

Overlap of the right anterior cingulate cortex (BA32) under cognition and resting conditions is also of interest. Anterior cingulate is a generic attention area, has a key mediatory role in the limbic-cortical model (Mayberg et al., 1999; Mayberg, 2003; Disner et al., 2011; Etkin et al., 2011) and is associated with reduction in brain volume in patients with MDD irrespective of mood state (Drevets et al., 2008). Increased activation of anterior cingulate in depressed patients suggests that they may need to work harder under cognitive demanding tasks compared to controls and that connectivity to this region is fundamentally altered, as evidenced during the resting condition. A salience network has been proposed, which has been hypothesized to be involved in switching of attention and the control of other networks within the brain (Seeley et al., 2007; Menon and Uddin, 2010). This network has been proposed to be anchored on the anterior cingulate cortex and given that this area has been identified to be altered in depression it would be of some interest to further investigate depression within the context of the salience network.

When performing a comparison of the meta-analyses of brain areas altered in depressed patients across the three conditions (emotion, cognition, and resting) at recommended cluster size thresholds, we found that there were no common areas of the brain that were significantly altered. This was unexpected $a$ priori but is consistent with the lack of significant overlap of the emotion and cognition meta-analyses. Right anterior cingulate and left thalamus were, however, identified across all three meta-analyses in our exploratory analysis. Anterior cingulate is a generic attention area, consistent with underlying low level attention demands of tasks and rest. The thalamus has a key role in relay of sensory information for cognition and emotion states and is part of both the limbic-cortical (Mayberg, 2003) and the cortical-striatal (Bora et al., 2012; Graham et al., 2013) models. In the limbic-cortical model, it plays a role in the reduced coordination with other components of the network (Mayberg, 2003; Drevets et al., 2008). It is known to be a source of the low frequency oscillatory potentials associated with arousal and coordination of cortical activity (Steriade et al., 1993; Malekmohammadi et al., 2014). Right thalamus was also identified in two of three conditions (cognition and resting). The putamen was also commonly identified, across hemispheres. Putamen is a key component of the corticostriatal model and is associated with information flow leading to motor planning and learning (Brovelli et al., 2011). Common areas of altered activity across the less demanding emotional valence and resting state were left parahippocampus, likely associated with the verbal face/object demands of the task, and left amygdala. Right insula was observed across emotion and cognition conditions. Interestingly, the regions are primarily subcortical involving limbic and striatal regions.

Support for the three neurobiological models of major depressive disorder, limbic-cortical, corticostriatal, and the default mode network, has been recently reviewed in the context of functional MRI literature involving cross-sectional studies comparing depressed patients and healthy controls and in treatment studies (Graham et al., 2013). In Graham et al.'s review, emotion, cognition, and resting conditions were combined, limiting the ability to identify the contribution of different task conditions to these complementary models. Our findings support differences in brain regions altered in depressed patients compared to healthy controls for the different task conditions. This was particularly 
evident for more demanding cognition versus emotion tasks as indicated above. While the main regions altered across our separate meta-analyses spanned regions identified in the three models, new insights of the potential contribution under different conditions may be gleaned. A relatively greater activation of limbic areas, i.e., bilateral amygdala and parahippocampal area in simple emotionally valenced tasks compared to cognitively demanding tasks, as well as overlap of amydgala and subcallosal cingulate in emotion and resting conditions, is consistent with the over activity of these regions described in the limbic-cortical model (Mayberg, 2003). In addition, the greater involvement of medial frontal, insula, and superior temporal regions in depressed patients compared to controls under cognitively demanding conditions compared to simple emotional conditions, may reflect the increased need for inhibition by these regions, also consistent with the limbic-cortical model (Mayberg et al., 1999; Mayberg, 2003). Common involvement of anterior cingulate, thalamus, and putamen across the different task conditions further supports the core role of subcortical striatal and limbic regions and the corticostriatal model (Bora et al., 2012), while overlap between resting and task conditions in amydgala, subcallosal cingulate, and anterior cingulate, highlights increased connectivity of these activated regions. We did not find clear support for changes in the default mode network in our resting condition meta-analysis. This is despite recent research targeting alterations in the default network as a possible marker of the disease (Ino et al., 2011; Baojuan et al., 2013; Silbersweig, 2013; Li et al., 2014). Together our findings provide support for the generally held view that depression is a systems-level disorder affecting integrated pathways linking select cortical, subcortical, and limbic sites (Mayberg, 2007). Our findings also provide support for brain network interactions as suggested by Menon (2011) and Pessoa (2014). This type of model would suggest that demand of the task will determine extent of network activation while clinical depression may dampen the efficiency of function and lead to a difference in brain activity between depressed and healthy controls whether doing a simple emotionally valenced task or lying in resting state. Further systematic investigation of alteration of networks is recommended.

\section{MEDICATION AND CLINICAL ASSESSMENT}

The effect that medication may have on the depressed patient's imaging results is still not clear. We reviewed the studies for the proportion of clinically depressed patients on medication in the named studies. Results revealed that in the emotion studies $48 \%$ of the depressed participants were medication free, while in the cognitive studies only $13 \%$ of the patients were medication-free and $43 \%$ were medication free in the resting-state studies. The exact effect of medication on the brain networks of patients diagnosed with depression remains relatively unknown in these samples and this may be significant as a variety of medications were used, including medications classified as serotonin-specific reuptake inhibitors, e.g., paroxetine, medications classified as serotonin and noradrenaline reuptake inhibitors such as venlafaxine, and drugs classified as tri-cyclic antidepressants such as amitriptyline. Unfortunately, the proportion of studies in each of three categories that involved medication-free depressed patients was quite low and did not allow for separate meta-analysis.
A range of clinical assessments were used to assess and quantify the level of depression in each patient in each study (Table 1). Although all the tests are generally accepted as measures of depression, there has been some suggestion by Kang et al. (2013) that the Beck depression index and Hamilton depression rating scale are more likely to misclassify patients with depression. This may have had implications for the studies involving these assessments.

\section{LIMITATIONS}

The task-based meta-analyses undertaken were categorized as "emotion" or "cognition" based on broad categorization of tasks from the original studies, creating potential problems for interpretation of results. The different tasks within a sub-group will influence the results across studies and the co-ordinates entered. For example, combining studies of simple cognitive but varying emotional stimuli, e.g., emotional face and emotional word tasks, may increase the spread of regions activated, reducing the likelihood of significant activation of a particular region across studies. Unfortunately, it was not possible to obtain a more homogenous group of studies with more similar tasks within the emotional or cognition processing groups. Despite this limitation, identification of common regions across studies is likely to be robust and suggestive of changes associated with depression if the tasks are of similar difficulty. While some studies did specify differences in performance on the task between depressed patients and healthy controls, this variation was not able to be interpreted in the context of our meta-analyses. The fact that some but not all depressed patients were medicated may also have an effect on results. Another limitation is the fact that in our resting meta-analysis, co-ordinates were taken from studies using different imaging techniques, correlation of BOLD fluctuations using fMRI, PET/SPECT with a range of labeling mechanisms (listed in Table 1), and ASL perfusion. Although all measure brain activity, typically via blood flow changes, the fact that different methods are used may have affected the sensitivity of the original results and introduced a level of noise.

\section{SUMMARY AND CONCLUSION}

Our quantitative co-ordinate based meta-analyses of brain regions altered in depressed patients compared to healthy controls highlight the role of different brain regions when performing simple emotionally valenced tasks compared to cognitively demanding tasks. In contrast, similar brain regions were altered under emotionally valenced and resting conditions. While findings have been previously reported under each of these conditions, our meta-analyses quantified the overlap and divergence under different task conditions. Identification of common and divergent brain regions under different task conditions provides new insight into the relationship between task condition and the current models of depression as well as the core role of different cortical, subcortical and limbic regions when a systems-level approach is taken. Key regions of overlap identified included amydgala and subcallosal cingulate (under emotionally valenced and resting conditions), and anterior cingulate (under cognitively demanding and resting conditions). In comparison, regions 
of divergence included bilateral amydgala/parahippocampus (emotion $>$ cognition), medial frontal, insula, and superior temporal (cognition $>$ emotion), and amygdala (resting $>$ cognition). The differential involvement of left amygdala in resting and emotional condition studies but not in cognition studies is noteworthy.

In conclusion, these findings support a relative increase of activity in subcortical limbic and striatal regions under emotionally valenced and resting conditions, while during cognitively demanding tasks medial frontal and insula regions are more active. Over activity of subcortical structures is consistent with cortico-limbic and striatal models. The relative increase of medial frontal and insula regions under cognitively demanding conditions supports the interpretation that depressed patients may need to work harder on the basis of capacity limited performance (Fitzgerald et al., 2008b; Pessoa, 2014). Identification of common and divergent brain regions may better inform current neurobiological models of depression and the mechanisms underlying.

\section{ACKNOWLEDGMENTS}

The authors would like to acknowledge the Commonwealth Scientific Industrial Research Organisation (CSIRO) preventative Health flagship grant. Leeanne M. Carey was supported by an Australian Research Council Future Fellowship (\#FT0992299). Susan M. Palmer is supported in part by the CSIRO preventative Health flagship grant. Leeanne M. Carey and Susan M. Palmer are grateful to the Victorian Government's Operational Infrastructure Support Program for support. Sheila G. Crewther acknowledges the support of NHMRC App10004740. Leeanne M. Carey acknowledges the support of NHMRC grant App1022694. No writing assistance was utilized in the production of this manuscript.

\section{REFERENCES}

American Psychiatric Association. (2013). DSM-5: Diagnostic and Statistical Manual of Mental Disorders, 5th Edn. Arlington, VA: American Psychiatric Publishing, 991.

Andrade, L., Caraveo-Anduaga, J. J., Berglund, P., Bijl, R. V., De Graaf, R., Vollebergh, W., et al. (2003). The epidemiology of major depressive episodes: results from the international consortium of psychiatric epidemiology (ICPE) surveys. Int. J. Methods Psychiatr. Res. 12, 3-21. doi:10.1002/mpr.138

Aron, A. R., Robbins, T. W., and Poldrack, R. A. (2004). Inhibition and the right inferior frontal cortex. Trends Cogn. Sci. 8, 170-177. doi:10.1016/j.tics.2004.02.010

Audenaert, K., Goethals, I., Van Laere, K., Lahorte, P., Brans, B., Versijpt, J., et al. (2002). SPECT neuropsychological activation procedure with the verbal fluency test in attempted suicide patients. Nucl. Med. Commun. 23, 907-916. doi:10.1097/00006231-200209000-00015

Baojuan, L., Liu, L., Friston, K. J., Shen, H., Wang, L., Zeng, L.-L., et al. (2013). A treatment-resistant default mode subnetwork in major depression. Biol. Psychiatry 74, 48-54. doi:10.1016/j.biopsych.2012.11.007

Bauer, I., Hughes, M., Rowsell, R., Cockerell, R., Pipingas, A., Crewther, S., et al. (2014). Omega-3 supplementation improves cognition and modifies brain activation in young adults. Hum. Psychopharmacol. 29, 133-144. doi:10.1002/ hup. 2379

Beck, A. T., Ward, C. H., Mendelson, M., Mock, J., and Erbaugh, J. (1961). An inventory for measuring depression. Arch. Gen. Psychiatry 4, 561-571. doi:10.1001/archpsyc.1961.01710120031004

Bench, C. J., Friston, K. J., Brown, R. G., Scott, L. C., Frackowiak, R. S., and Dolan, R. J. (1992). The anatomy of melancholia-focal abnormalities of cerebral blood flow in major depression. Psychol. Med. 22, 607-615. doi:10.1017/ S003329170003806X
Berman, M. G., and Jonides, J. (2011). Ruminating on rumination. Biol. Psychiatry 70, 310-311. doi:10.1016/j.biopsych.2011.06.003

Berman, M. G., Peltier, S., Nee, D. E., Kross, E., Deldin, P. J., and Jonides, J. (2010). Depression, rumination and the default network. Soc. Cogn. Affect. Neurosci. 6, 548-555. doi:10.1093/scan/nsq080

Bora, E., Harrison, B. J., Davey, C. G., Yücel, M., and Pantelis, C. (2012). Metaanalysis of volumetric abnormalities in cortico-striatal-pallidal-thalamic circuits in major depressive disorder. Psychol. Med. 42, 671-681. doi:10.1017/ S0033291711001668

Bremner, J. D., Vythilingam, M., Vermetten, E., and Charney, D. S. (2007). Effects of antidepressant treatment on neural correlates of emotional and neutral declarative verbal memory in depression. J. Affect. Disord. 101, 99-111. doi:10.1016/j.jad.2006.10.028

Bremner, J. D., Vythilingam, M., Vermetten, E., Vaccarino, V., and Charney, D. S. (2004). Deficits in hippocampal and anterior cingulate functioning during verbal declarative memory encoding in midlife major depression. Am. J. Psychiatry 161, 637-645. doi:10.1176/appi.ajp.161.4.637

Brody, A. L., Saxena, S., Stoessel, P., Gillies, L. A., Fairbanks, L. A., Alborzian, S., et al. (2001). Regional brain metabolic changes in patients with major depression treated with either paroxetine or interpersonal therapy: preliminary findings. Arch. Gen. Psychiatry 58, 631-640. doi:10.1001/archpsyc.58.7.631

Brovelli, A., Nazarian, B., Meunier, M., and Boussaoud, D. (2011). Differential roles of caudate nucleus and putamen during instrumental learning. Neuroimage 57, 1580-1590. doi:10.1016/j.neuroimage.2011.05.059

Canli, T., Sivers, H., Thomason, M. E., Whitfield-Gabrieli, S., Gabrieli, J. D., and Gotlib, I. H. (2004). Brain activation to emotional words in depressed vs healthy subjects. Neuroreport 15, 2585-2588.

Carballedo, A., Scheuerecker, J., Meisenzahl, E., Schoepf, V., Bokde, A., Möller, H.-J., et al. (2011). Functional connectivity of emotional processing in depression. $J$. Affect. Disord. 134, 272-279. doi:10.1016/j.jad.2011.06.021

Chiong, W., Wilson, S. M., D’Esposito, M., Kayser, A. S., Grossman, S. N., Poorzand, P., et al. (2013). The salience network causally influences default mode network activity during moral reasoning. Brain 136, 1929-1941. doi:10.1093/brain/ awt066

Clement, H., Mayberg, H., Stone, S., Laxton, A., Haber, S., and Lozano, A. M. (2011). The subcallosal cingulate gyrus in the context of major depression. Biol. Psychiatry 69, 301-308. doi:10.1016/j.biopsych.2010.09.034

de Asis, J. M., Stern, E., Alexopoulos, G. S., Pan, H., Van Gorp, W., Blumberg, H., et al. (2001). Hippocampal and anterior cingulate activation deficits in patients with geriatric depression. Am. J. Psychiatry 158, 1321-1323. doi:10.1176/appi. ajp.158.8.1321

Dichter, G. S., Felder, J. N., and Smoski, M. J. (2009). Affective context interferes with cognitive control in unipolar depression: an fMRI investigation. J. Affect. Disord. 114, 131-142. doi:10.1016/j.jad.2008.06.027

Diener, C., Kuehner, C., Brusniak, W., Ubl, B., Wessa, M., and Flor, H. (2012). A metaanalysis of neurofunctional imaging studies of emotion and cognition in major depression. Neuroimage 61, 677-685. doi:10.1016/j.neuroimage.2012.04.005

Disner, S. G., Beevers, C. G., Haigh, E. A., and Beck, A. T. (2011). Neural mechanisms of the cognitive model of depression. Nat. Rev. Neurosci. 12, 467-477. doi:10.1038/nrn3027

Drevets, W. C. (2000). Neuroimaging studies of mood disorders. Biol. Psychiatry 48 , 813-829. doi:10.1016/S0006-3223(00)01020-9

Drevets, W. C., Price, J. L., and Furey, M. L. (2008). Brain structural and functional abnormalities in mood disorders: implications for neurocircuitry models of depression. Brain Struct. Funct. 213, 93-118. doi:10.1007/s00429-0080189-x

Drevets, W. C., Videen, T. O., Price, J. L., Preskorn, S. H., Carmichael, S. T., and Raichle, M. E. (1992). A functional anatomical study of unipolar depression. $J$. Neurosci. 12, 3628-3641.

Duhameau, B., Ferré, J.-C., Jannin, P., Gauvrit, J.-Y., Vérin, M., Millet, B., et al. (2010). Chronic and treatment-resistant depression: a study using arterial spin labeling perfusion MRI at 3Tesla. Psychiatry Res. 182, 111-116. doi:10.1016/j.pscychresns. 2010.01.009

Egner, T. (2009). Prefrontal cortex and cognitive control: motivating functional hierarchies. Nat. Neurosci. 12, 821-822. doi:10.1038/nn0709-821

Eickhoff, S. B., Bzdok, D., Laird, A. R., Kurth, F., and Fox, P. T. (2012). Activation likelihood estimation meta-analysis revisited. Neuroimage 59, 2349-2361. doi:10.1016/j.neuroimage.2011.09.017 
Eickhoff, S. B., Bzdok, D., Laird, A. R., Roski, C., Caspers, S., Zilles, K., et al. (2011). Co-activation patterns distinguish cortical modules, their connectivity and functional differentiation. Neuroimage 57, 938-949. doi:10.1016/j.neuroimage.2011. 05.021

Eickhoff, S. B., Laird, A. R., Grefkes, C., Wang, L. E., Zilles, K., and Fox, P. T. (2009). Coordinate-based activation likelihood estimation meta-analysis of neuroimaging data: a random-effects approach based on empirical estimates of spatial uncertainty. Hum. Brain Mapp. 30, 2907-2926. doi:10.1002/hbm.20718

Elliott, R., Baker, S. C., Rogers, R. D., O'Leary, D. A., Paykel, E. S., Frith, C. D., et al. (1997). Prefrontal dysfunction in depressed patients performing a complex planning task: a study using positron emission tomography. Psychol. Med. 27, 931-942. doi:10.1017/S0033291797005187

Elliott, R., Rubinsztein, J. S., Sahakian, B. J., and Dolan, R. J. (2002). The neural basis of mood-congruent processing biases in depression. Arch. Gen. Psychiatry 59, 597-604. doi:10.1001/archpsyc.59.7.597

Epstein, J., Pan, H., Kocsis, J. H., Yang, Y., Butler, T., Chusid, J., et al. (2006). Lack of ventral striatal response to positive stimuli in depressed versus normal subjects. Am. J. Psychiatry 163, 1784-1790. doi:10.1176/appi.ajp.163.10.1784

Etkin, A., Egner, T., and Kalisch, R. (2011). Emotional processing in anterior cingulate and medial prefrontal cortex. Trends Cogn. Sci. 15, 85-93. doi:10.1016/j.tics. 2010.11.004

First, M. B., Spitzer, R. L., Gibbon, M., and Williams, J. B. (1995). Structured clinical interview for DSM-IV axis I disorders, Patient Edition, January 1995 FINAL: SCID-I/P Version 2.0. New York: Biometrics Research Department, New York State Psychiatric Institute.

Fitzgerald, P. B., Laird, A. R., Maller, J., and Daskalakis, Z. J. (2008a). A metaanalytic study of changes in brain activation in depression. Hum. Brain Mapp. 29, 683-695. doi:10.1002/hbm.20613

Fitzgerald, P. B., Srithiran, A., Benitez, J., Daskalakis, Z. Z., Oxley, T. J., Kulkarni, J., et al. (2008b). An fMRI study of prefrontal brain activation during multiple tasks in patients with major depressive disorder. Hum. Brain Mapp. 29, 490-501. doi:10.1002/hbm.20414

Fox, M. D., Snyder, A. Z., Vincent, J. L., and Raichle, M. E. (2007). Intrinsic fluctuations within cortical systems account for intertrial variability in human behavior. Neuron 56, 171-184. doi:10.1016/j.neuron.2007.08.023

Fu, C. H. Y., Williams, S. C. R., Cleare, A. J., Brammer, M. J., Walsh, N. D., Kim, J., et al. (2004). Attenuation of the neural response to sad faces in major depression by antidepressant treatment: a prospective, event-related functional magnetic resonance imaging study. Arch. Gen. Psychiatry 61, 877-889. doi:10.1001/archpsyc.61.9.877

Fu, C., Williams, S., Brammer, M., Suckling, J., Kim, J., Cleare, A., et al. (2007). Neural responses to happy facial expressions in major depression following antidepressant treatment. Am. J. Psychiatry 164, 599-607. doi:10.1176/ajp.2007.164. 4.599

Gotlib, I. H., Sivers, H., Gabrieli, J. D. E., Whitfield-Gabrieli, S., Goldin, P., Minor, K. L., et al. (2005). Subgenual anterior cingulate activation to valenced emotional stimuli in major depression. Neuroreport 16, 1731-1734. doi:10.1097/01.wnr. 0000183901.70030 .82

Graham, J., Salimi-Khorshidi, G., Hagan, C., Walsh, N., Goodyer, I., Lennox, B., et al. (2013). Meta-analytic evidence for neuroimaging models of depression: state or trait? J. Affect. Disord. 151, 423-431. doi:10.1016/j.jad.2013.07.002

Greicius, M. D., Flores, B. H., Menon, V., Glover, G. H., Solvason, H. B., Kenna, H., et al. (2007). Resting-state functional connectivity in major depression: abnormally increased contributions from subgenual cingulate cortex and thalamus. Biol. Psychiatry 62, 429-437. doi:10.1016/j.biopsych.2006.09.020

Grimm, S., Beck, J., Schuepbach, D., Hell, D., Boesiger, P., Bermpohl, F., et al. (2008). Imbalance between left and right dorsolateral prefrontal cortex in major depression is linked to negative emotional judgment: an fMRI study in severe major depressive disorder. Biol. Psychiatry 63, 369-376. doi:10.1016/j.biopsych.2007. 05.033

Grimm, S., Ernst, J., Boesiger, P., Schuepbach, D., Hell, D., Boeker, H., et al. (2009). Increased self-focus in major depressive disorder is related to neural abnormalities in subcortical-cortical midline structures. Hum. Brain Mapp. 30, 2617-2627. doi:10.1002/hbm.20693

Haber, S. N., and Calzavara, R. (2009). The cortico-basal ganglia integrative network: the role of the thalamus. Brain Res. Bull. 78, 69-74. doi:10.1016/j.brainresbull. 2008.09.013

Haier, R. J., Siegel, B. V. Jr., Nuechterlein, K. H., Hazlett, E., Wu, J. C., Paek, J., et al. (1988). Cortical glucose metabolic rate correlates of abstract reasoning and attention studied with positron emission tomography. Intelligence 12, 199-217. doi:10.1016/j.neubiorev.2009.04.001

Haier, R. J., White, N. S., and Alkire, M. T. (2003). Individual differences in general intelligence correlate with brain function during nonreasoning tasks. Intelligence 31, 429-441. doi:10.1016/S0160-2896(03)00025-4

Halari, R., Simic, M., Pariante, C. M., Papadopoulos, A., Cleare, A., Brammer, M., et al. (2009). Reduced activation in lateral prefrontal cortex and anterior cingulate during attention and cognitive control functions in medication-naïve adolescents with depression compared to controls. J. Child Psychol. Psychiatry 50, 307-316. doi:10.1111/j.1469-7610.2008.01972.x

Hamani, C., Mayberg, H., Stone, S., Laxton, A., Haber, S., and Lozano, A. M. (2011). The subcallosal cingulate gyrus in the context of major depression. Biol. Psychiatry 69, 301-308. doi:10.1016/j.biopsych.2010.09.034

Hamilton, J. P., Etkin, A., Furman, D. J., Lemus, M. G., Johnson, R. F., and Gotlib, I. H. (2012). Functional neuroimaging of major depressive disorder: a metaanalysis and new integration of base line activation and neural response data. Am. J. Psychiatry 169, 693-703. doi:10.1176/appi.ajp.2012.11071105

Hamilton, J. P., Furman, D. J., Chang, C., Thomason, M. E., Dennis, E., and Gotlib, I. H. (2011). Default-mode and task-positive network activity in major depressive disorder: implications for adaptive and maladaptive rumination. Biol. Psychiatry 70, 327-333. doi:10.1016/j.biopsych.2011.02.003

Hamilton, M. (1960). A rating scale for depression. J. Neurol. Neurosurg. Psychiatry 23, 56-62. doi:10.1136/jnnp.23.1.56

Harvey, P.-O., Fossati, P., Pochon, J.-B., Levy, R., Lebastard, G., Lehéricy, S., et al. (2005). Cognitive control and brain resources in major depression: an fMRI study using the n-back task. Neuroimage 26, 860-869. doi:10.1016/j.neuroimage. 2005.02.048

Holmes, A. J., MacDonald, A. III, Carter, C. S., Barch, D. M., Andrew Stenger, V., and Cohen, J. D. (2005). Prefrontal functioning during context processing in schizophrenia and major depression: an event-related fMRI study. Schizophr. Res. 76, 199-206. doi:10.1016/j.schres.2005.01.021

Holtzheimer, P. E., and Mayberg, H. S. (2011). Stuck in a rut: rethinking depression and its treatment. Trends Neurosci. 34, 1-9. doi:10.1016/j.tins.2010.10.004

Hsu, D. T., Langenecker, S. A., Kennedy, S. E., Zubieta, J.-K., and Heitzeg, M. M. (2010). fMRI BOLD responses to negative stimuli in the prefrontal cortex are dependent on levels of recent negative life stress in major depressive disorder. Psychiatry Res. 183, 202-208. doi:10.1016/j.pscychresns.2009.12.002

Hugdahl, K., Rund, B. R., Lund, A., Asbjørnsen, A., Egeland, J., Ersland, L., et al. (2004). Brain activation measured with fMRI during a mental arithmetic task in schizophrenia and major depression. Am. J. Psychiatry 161, 286-293. doi:10.1176/appi.ajp.161.2.286

Ino, T., Nakai, R., Azuma, T., Kimura, T., and Fukuyama, H. (2011). Brain activation during autobiographical memory retrieval with special reference to default mode network. Open Neuroimag. J. 5, 14-23. doi:10.2174/1874440001105010014

Ito, H., Kawashima, R., Awata, S., Ono, S., Sato, K., Goto, R., et al. (1996). Hypoperfusion in the limbic system and prefrontal cortex in depression: SPECT with anatomic standardization technique. J. Nucl. Med. 37, 410-414.

Kang, H.-J., Stewart, R., Kim, J.-M., Jang, J.-E., Kim, S.-Y., Bae, K.-Y., et al. (2013). Comparative validity of depression assessment scales for screening poststroke depression. J. Affect. Disord. 147, 186-191. doi:10.1016/j.jad.2012.10.035

Keedwell, P. A., Andrew, C., Williams, S. C. R., Brammer, M. J., and Phillips, M. L. (2005). A double dissociation of ventromedial prefrontal cortical responses to sad and happy stimuli in depressed and healthy individuals. Biol. Psychiatry 58, 495-503. doi:10.1016/j.biopsych.2005.04.035

Kennedy, S. H., Evans, K. R., Krüger, S., Mayberg, H. S., Meyer, J. H., McCann, S., et al. (2001). Changes in regional brain glucose metabolism measured with positron emission tomography after paroxetine treatment of major depression. Am. J. Psychiatry 158, 899-905. doi:10.1176/appi.ajp.158.987.899

Kimbrell, T. A., Ketter, T. A., George, M. S., Little, J. T., Benson, B. E., Willis, M. W., et al. (2002). Regional cerebral glucose utilization in patients with a range of severities of unipolar depression. Biol. Psychiatry 51, 237-252. doi:10.1016/S0006-3223(01)01216-1

Kühn, S., and Gallinat, J. (2013). Resting-state brain activity in schizophrenia and major depression: a quantitative meta-analysis. Schizophr. Bull. 39, 358-365. doi:10.1093/schbul/sbr151

Kumari, V., Mitterschiffthaler, M. T., Teasdale, J. D., Malhi, G. S., Brown, R. G., Giampietro, V., et al. (2003). Neural abnormalities during cognitive generation of affect in treatment-resistant depression. Biol. Psychiatry 54, 777-791. doi:10.1016/S0006-3223(02)01785-7 
Laird, A. R., Robinson, J. L., McMillan, K. M., Tordesillas-Gutiérrez, D., Moran, S. T., Gonzales, S. M., et al. (2010). Comparison of the disparity between Talairach and MNI coordinates in functional neuroimaging data: validation of the Lancaster transform. Neuroimage 51, 677-683. doi:10.1016/j.neuroimage.2010.02.048

Lancaster, J. L., Tordesillas-Gutiérrez, D., Martinez, M., Salinas, F., Evans, A., Zilles, K., et al. (2007). Bias between MNI and Talairach coordinates analyzed using the ICBM-152 brain template. Hum. Brain Mapp. 28, 1194-1205. doi:10.1002/hbm.20345

Lanteaume, L., Khalfa, S., Régis, J., Marquis, P., Chauvel, P., and Bartolomei, F. (2007). Emotion induction after direct intracerebral stimulations of human amygdala. Cereb. Cortex 17, 1307-1313. doi:10.1093/cercor/bhl041

Lawrence, N. S., Williams, A. M., Surguladze, S., Giampietro, V., Brammer, M. J., Andrew, C., et al. (2004). Subcortical and ventral prefrontal cortical neural responses to facial expressions distinguish patients with bipolar disorder and major depression. Biol. Psychiatry 55, 578-587. doi:10.1016/j.biopsych. 2003.11.017

Li, X., Wu, H., Lou, C., Xing, B., and Yu, E. (2014). Study on the executive function of attention in depression patients based on SPECT technology. Int. J. Clin. Exp. Med. 7, 1110-1115.

Liu, C.-H., Jing, B., Ma, X., Xu, P.-F., Zhang, Y., Li, F., et al. (2014). Voxel-based morphometry study of the insular cortex in female patients with current and remitted depression. Neuroscience 262, 190-199. doi:10.1016/j.neuroscience.2013.12.058

Liu, Z., Xu, C., Xu, Y., Wang, Y., Zhao, B., Lv, Y., et al. (2010). Decreased regional homogeneity in insula and cerebellum: a resting-state fMRI study in patients with major depression and subjects at high risk for major depression. Psychiatry Res. 182, 211-215. doi:10.1016/j.pscychresns.2010.03.004

MacHale, S. M., Lawrie, S. M., Cavanagh, J. T., Glabus, M. F., Murray, C. L., Goodwin, G. M., et al. (2000). Cerebral perfusion in chronic fatigue syndrome and depression. Br. J. Psychiatry 176, 550-556. doi:10.1192/bjp.176.6.550

Malekmohammadi, M., Elias, W. J., and Pouratian, N. (2014). Human thalamus regulates cortical activity via spatially specific and structurally constrained phaseamplitude coupling. Cereb. Cortex. doi:10.1093/cercor/bht358

Mandell, D., Siegle, G. J., Shutt, L., Feldmiller, J., and Thase, M. E. (2014). Neural substrates of trait ruminations in depression. J. Abnorm. Psychol. 123, 35-48. doi: $10.1037 / \mathrm{a} 0035834$

Matsuo, K., Glahn, D. C., Peluso, M. A. M., Hatch, J. P., Monkul, E. S., Najt, P., et al. (2007). Prefrontal hyperactivation during working memory task in untreated individuals with major depressive disorder. Mol. Psychiatry 12, 158-166. doi:10.1038/sj.mp.4001894

Mayberg, H. S. (1997). Limbic-cortical dysregulation: a proposed model of depression. J. Neuropsychiatry Clin. Neurosci. 9, 471-481.

Mayberg, H. S. (2003). Modulating dysfunctional limbic-cortical circuits in depression: towards development of brain-based algorithms for diagnosis and optimised treatment. Br. Med. Bull. 65, 193-207. doi:10.1093/bmb/65.1.193

Mayberg, H. S. (2007). Defining the neural circuitry of depression: toward a new nosology with therapeutic implications. Biol. Psychiatry 61, 729-730. doi:10.1016/j.biopsych.2007.01.013

Mayberg, H. S., Liotti, M., Brannan, S. K., McGinnis, S., Mahurin, R. K., Jerabek, P. A., et al. (1999). Reciprocal limbic-cortical function and negative mood: converging PET findings in depression and normal sadness. Am. J. Psychiatry 156, 675-682. doi:10.1176/ajp.156.5.675

Mayberg, H. S., Lozano, A. M., Voon, V., McNeely, H. E., Seminowicz, D., Hamani, C., et al. (2005). Deep brain stimulation for treatment-resistant depression. Neuron 45, 651-660. doi:10.1016/j.neuron.2005.02.014

Menon, V. (2011). Large-scale brain networks and psychopathology: a unifying triple network model. Trends Cogn. Sci. 15, 483-506. doi:10.1016/j.tics.2011.08.003

Menon, V., and Uddin, L. Q. (2010). Saliency, switching, attention and control: a network model of insula function. Brain Struct. Funct. 214, 655-667. doi:10.1007/s00429-010-0262-0

Mingtian, Z., Shuqiao, Y., Xiongzhao, Z., Jinyao, Y., Xueling, Z., Xiang, W., et al. (2012). Elevated amygdala activity to negative faces in young adults with early onset major depressive disorder. Psychiatry Res. 201, 107-112. doi:10.1016/j. pscychresns.2011.06.003

Mitterschiffthaler, M. T., Kumari, V., Malhi, G. S., Brown, R. G., Giampietro, V. P., Brammer, M. J., et al. (2003). Neural response to pleasant stimuli in anhedonia: an fMRI study. Neuroreport 14, 177-182. doi:10.1097/00001756-20030210000003

Mitterschiffthaler, M. T., Williams, S. C. R., Walsh, N. D., Cleare, A. J., Donaldson, C., Scott, J., et al. (2008). Neural basis of the emotional Stroop interference effect in major depression. Psychol. Med. 38, 247-256. doi:10.1017/ S0033291707001523

Monkul, E. S., Silva, L. A. P., Narayana, S., Peluso, M. A. M., Zamarripa, F., Nery, F. G., et al. (2012). Abnormal resting state corticolimbic blood flow in depressed unmedicated patients with major depression: a (15)O-H(2)O PET study. Hum. Brain Mapp. 33, 272-279. doi:10.1002/hbm.21212

Montgomery, S. A., and Asberg, M. (1979). A new depression scale designed to be sensitive to change. Br. J. Psychiatry 134, 382-389. doi:10.1192/bjp.134.4.382

Oda, K., Okubo, Y., Ishida, R., Murata, Y., Ohta, K., Matsuda, T., et al. (2003). Regional cerebral blood flow in depressed patients with white matter magnetic resonance hyperintensity. Biol. Psychiatry 53, 150-156. doi:10.1016/S0006-3223(02) 01548-2

Okada, G., Okamoto, Y., Morinobu, S., Yamawaki, S., and Yokota, N. (2003). Attenuated left prefrontal activation during a verbal fluency task in patients with depression. Neuropsychobiology 47, 21-26. doi:10.1159/000068871

Peng, D.-H., Jiang, K.-D, Fang, Y.-R., Xu, Y.-F., Shen, T., Long, X.-Y., et al. (2011). Decreased regional homogeneity in major depression as revealed by resting-state functional magnetic resonance imaging. Chin. Med. J. 124, 369-373.

Périco, C. A.-M., Skaf, C. R., Yamada, A., Duran, F., Buchpiguel, C. A., Castro, C. C., et al. (2005). Relationship between regional cerebral blood flow and separate symptom clusters of major depression: a single photon emission computed tomography study using statistical parametric mapping. Neurosci. Lett. 384, 265-270. doi:10.1016/j.neulet.2005.04.088

Pessoa, L. (2008). On the relationship between emotion and cognition. Nat. Rev. Neurosci. 9, 148-158. doi:10.1038/nrn2317

Pessoa, L. (2014). Précis of the cognitive-emotional brain. Behav. Brain Sci. 10, 1-66. doi:10.1017/S0140525X14000120

Pizzagalli, D. A. (2011). Frontocingulate dysfunction in depression: toward biomarkers of treatment response. Neuropsychopharmacology 36, 183-206. doi:10. 1038/npp.2010.166

Posamentier, M. T., and Abdi, H. (2003). Processing faces and facial expressions. Neuropsychol. Rev. 13, 113-143. doi:10.1023/A:1025519712569

Radloff, L. S. (1977). The CES-D scale: a self-report depression scale for research in the general population. Appl. Psychol. Meas. 1, 385-401. doi:10.1177/ 014662167700100306

Raichle, M. E., MacLeod, A. M., Snyder, A. Z., Powers, W. J., Gusnard, D. A., and Shulman, G. L. (2001). A default mode of brain function. Proc. Natl. Acad. Sci. U.S.A. 98, 676-682. doi:10.1073/pnas.98.2.676

Remijnse, P. L., Nielen, M. M. A., van Balkom, A. J. L. M., Hendriks, G.-J., Hoogendijk, W. J., Uylings, H. B. M., et al. (2009). Differential frontal-striatal and paralimbic activity during reversal learning in major depressive disorder and obsessive-compulsive disorder. Psychol. Med. 39, 1503-1518. doi:10.1017/ S0033291708005072

Ritchey, M., Dolcos, F., Eddington, K. M., Strauman, T. J., and Cabeza, R. (2011). Neural correlates of emotional processing in depression: changes with cognitive behavioral therapy and predictors of treatment response. J. Psychiatry Res. 45, 577-587. doi:10.1016/j.jpsychires.2010.09.007

Rottschy, C., Langer, R., Dogan, I., Reetz, K., Laird, A. R., Schulz, J. B., et al. (2012). Modelling neural correlates of working memory: a coordinate-based metaanalysis. Neuroimage 60, 830-846. doi:10.1016/j.neuroimage.2011.11.050

Saxena, S., Brody, A. L., Ho, M. L., Alborzian, S., Ho, M. K., Maidment, K. M., et al. (2001). Cerebral metabolism in major depression and obsessive-compulsive disorder occurring separately and concurrently. Biol. Psychiatry 50, 159-170. doi:10.1016/S0006-3223(01)01123-4

Seeley, W. W., Menon, V., Schatzberg, A. F., Keller, J., Glover, G. H., Kenna, H., et al. (2007). Dissociable intrinsic connectivity networks for salience processing and executive control. J. Neurosci. 27, 2349-2356. doi:10.1523/JNEUROSCI.5587-06. 2007

Sexton, C. E., Mackay, C. E., and Ebmeier, K. P. (2012). A systematic review and meta-analysis of magnetic resonance imaging studies in late-life depression. Am. J. Geriatr. Psychiatry 21, 184-195. doi:10.1016/j.jagp.2012.10.019

Sheline, Y. I., Barch, D. M., Price, J. L., Rundle, M. M., Vaishnavi, S. N., Snyder, A. Z., et al. (2009). The default mode network and self-referential processes in depression. Proc. Natl. Acad. Sci. U.S.A. 106, 1942-1947. doi:10.1073/pnas. 0812686106

Siegle, G. J., Steinhauer, S. R., Thase, M. E., Stenger, V. A., and Carter, C. S. (2002). Can't shake that feeling: event-related fMRI assessment of sustained amygdala activity in response to emotional information in depressed individuals. Biol. Psychiatry 51, 693-707. doi:10.1016/S0006-3223(02)01314-8 
Siegle, G. J., Thompson, W., Carter, C. S., Steinhauer, S. R., and Thase, M. E. (2007). Increased amygdala and decreased dorsolateral prefrontal BOLD responses in unipolar depression: related and independent features. Biol. Psychiatry 61, 198-209. doi:10.1016/j.biopsych.2006.05.048

Silbersweig, D. (2013). Default mode subnetworks, connectivity, depression and its treatment: toward brain-based biomarker development. Biol. Psychiatry 74, 5-6. doi:10.1016/j.biopsych.2013.05.011

Skaf, C. R., Yamada, A., Garrido, G. E. J., Buchpiguel, C. A., Akamine, S., Castro, C. C., et al. (2002). Psychotic symptoms in major depressive disorder are associated with reduced regional cerebral blood flow in the subgenual anterior cingulate cortex: a voxel-based single photon emission computed tomography (SPECT) study. J. Affect. Disord. 68, 295-305. doi:10.1016/S0165-0327(00)00365-7

Steriade, M., McCormick, D. A., and Sejnowski, T. J. (1993). Thalamocortical oscillations in the sleeping and aroused brain. Science 262, 679-685. doi:10.1126/ science. 8235588

Stuhrmann, A., Suslow, T., and Dannlowski, U. (2011). Facial emotion processing in major depression: a systematic review of neuroimaging findings. Biol. Mood Anxiety Disord. 1, 10. doi:10.1186/2045-5380-1-10

Surguladze, S., Brammer, M. J., Keedwell, P., Giampietro, V., Young, A. W., Travis, M. J., et al. (2005). A differential pattern of neural response toward sad versus happy facial expressions in major depressive disorder. Biol. Psychiatry 57, 201-209. doi:10.1016/j.biopsych.2004.10.028

Surguladze, S. A., El-Hage, W., Dalgleish, T., Radua, J., Gohier, B., and Phillips, M. L. (2010). Depression is associated with increased sensitivity to signals of disgust: a functional magnetic resonance imaging study. J. Psychiatry Res. 44, 894-902. doi:10.1016/j.jpsychires.2010.02.010

Taylor Tavares, J. V., Clark, L., Furey, M. L., Williams, G. B., Sahakian, B. J., and Drevets, W. C. (2008). Neural basis of abnormal response to negative feedback in unmedicated mood disorders. Neuroimage 42, 1118-1126. doi:10.1016/ j.neuroimage.2008.05.049

Townsend, J. D., Eberhart, N. K., Bookheimer, S. Y., Eisenberger, N. I., FolandRoss, L. C., Cook, I. A., et al. (2010). fMRI activation in the amygdala and the orbitofrontal cortex in unmedicated subjects with major depressive disorder. Psychiatry Res. 183, 209-217. doi:10.1016/j.pscychresns.2010.06.001

Tremblay, L. K., Naranjo, C. A., Graham, S. J., Herrmann, N., Mayberg, H. S., Hevenor, S., et al. (2005). Functional neuroanatomical substrates of altered reward processing in major depressive disorder revealed by a dopaminergic probe. Arch. Gen. Psychiatry 62, 1228-1236. doi:10.1001/archpsyc.62.11.1228

Turkeltaub, P. E., Eickhoff, S. B., Laird, A. R., Fox, M., Wiener, M., and Fox, P. (2012). Minimizing within-experiment and within-group effects in activation likelihood estimation meta-analyses. Hum. Brain Mapp. 33, 1-13. doi:10.1002/hbm.21186

van Eijndhoven, P., van Wingen, G., Fernández, G., Rijpkema, M., Verkes, R. J., Buitelaar, J., et al. (2011). Amygdala responsivity related to memory of emotionally neutral stimuli constitutes a trait factor for depression. Neuroimage 54, 1677-1684. doi:10.1016/j.neuroimage.2010.08.040

Veer, I. M., Beckmann, C. F., van Tol, M.-J., Ferrarini, L., Milles, J., Veltman, D. J., et al. (2010). Whole brain resting-state analysis reveals decreased functional connectivity in major depression. Front. Syst. Neurosci. 4:41. doi:10.3389/fnsys. 2010.00041

Videbech, P., Ravnkilde, B., Pedersen, A. R., Egander, A., Landbo, B., Rasmussen, N. A., et al. (2001). The Danish PET/depression project: PET findings in patients with major depression. Psychol. Med. 31, 1147-1158. doi:10.1017/ S0033291701004469
Wang, L., Hermens, D. F., Hickie, I. B., and Lagopoulos, J. (2012). A systematic review of resting-state functional-MRI studies in major depression. J. Affect. Disord. 142, 6-12. doi:10.1016/j.jad.2012.04.013

Wang, L., Krishnan, K. R., Steffens, D. C., Potter, G. G., Dolcos, F., and McCarthy, G. (2008a). Depressive state- and disease-related alterations in neural responses to affective and executive challenges in geriatric depression. Am. J. Psychiatry 165, 863-871. doi:10.1176/appi.ajp.2008.07101590

Wang, L., LaBar, K. S., Smoski, M., Rosenthal, M. Z., Dolcos, F., Lynch, T. R., et al. (2008b). Prefrontal mechanisms for executive control over emotional distraction are altered in major depression. Psychiatry Res. 163, 143-155. doi:10.1016/j.pscychresns.2007.10.004

Werner, N. S., Meindl, T., Materne, J., Engel, R. R., Huber, D., Riedel, M., et al. (2009). Functional MRI study of memory-related brain regions in patients with depressive disorder. J. Affect. Disord. 119, 124-131. doi:10.1016/j.jad.2009.03.003

World Health Organization. (2012). Depression. A Global Public Health Concern. Available at: http://www.who.int/mental_health/management/depression/who paper_depression_wfmh_2012.pdf

Wu, Q.-Z., Li, D.-M., Kuang, W.-H., Zhang, T.-J., Lui, S., Huang, X.-Q., et al. (2011). Abnormal regional spontaneous neural activity in treatment-refractory depression revealed by resting-state fMRI. Hum. Brain Mapp. 32, 1290-1299. doi: $10.1002 / \mathrm{hbm} .21108$

Yao, Z., Wang, L., Lu, Q., Liu, H., and Teng, G. (2009). Regional homogeneity in depression and its relationship with separate depressive symptom clusters: a resting-state fMRI study. J. Affect. Disord. 115, 430-438. doi:10.1016/j.jad.2008. 10.013

Yoshimura, S., Okamoto, Y., Onoda, K., Matsunaga, M., Ueda, K., Suzuki, S., et al. (2010). Rostral anterior cingulate cortex activity mediates the relationship between the depressive symptoms and the medial prefrontal cortex activity. $J$. Affect. Disord. 122, 76-85. doi:10.1016/j.jad.2009.06.017

Young, K. D., Erickson, K., Nugent, A. C., Fromm, S. J., Mallinger, A. G., Furey, M. L., et al. (2012). Functional anatomy of autobiographical memory recall deficits in depression. Psychol. Med. 42, 345-357. doi:10.1017/S0033291711001371

Zhong, M., Wang, X., Xiao, J., Yi, J., Zhu, X., Liao, J., et al. (2011). Amygdala hyperactivation and prefrontal hypoactivation in subjects with cognitive vulnerability to depression. Biol. Psychol. 88, 233-242. doi:10.1016/j.biopsycho.2011.08.007

Conflict of Interest Statement: The authors declare that the research was conducted in the absence of any commercial or financial relationships that could be construed as a potential conflict of interest.

Received: 07 May 2014; accepted: 15 December 2014; published online: 14 January 2015 .

Citation: Palmer SM, Crewther SG, Carey LM and The START Project Team (2015) A meta-analysis of changes in brain activity in clinical depression. Front. Hum. Neurosci. 8:1045. doi: 10.3389/fnhum.2014.01045

This article was submitted to the journal Frontiers in Human Neuroscience.

Copyright (c) 2015 Palmer, Crewther, Carey and The START Project Team. This is an open-access article distributed under the terms of the Creative Commons Attribution License (CC BY). The use, distribution or reproduction in other forums is permitted, provided the original author(s) or licensor are credited and that the original publication in this journal is cited, in accordance with accepted academic practice. No use, distribution or reproduction is permitted which does not comply with these terms. 